Article

\title{
Deep Sequencing MicroRNAs from Extracellular Membrane Vesicles Revealed the Association of the Vesicle Cargo with Cellular Origin
}

\author{
Uyen Thi Trang Than ${ }^{1}$, Dominic Guanzon ${ }^{2}$, James A Broadbent ${ }^{3}$, Tony J Parker ${ }^{2,3}$ and \\ David I Leavesley ${ }^{3,4, *(\mathbb{B})}$ \\ 1 Vinmec Research Institute of Stem Cell and Gene Technology, Vinmec Health Care System, Ha Noi 10000, \\ Vietnam; v.uyenttt@vinmec.com \\ 2 Tissue Repair and Translational Physiology Program, Institute of Health and Biomedical Innovation, \\ Queensland University of Technology, Kelvin Grove, QLD 4059, Australia; \\ dominic.guanzon@gmail.com (D.G.); a.parker@qut.edu.au (T.J.P.) \\ 3 School of Biomedical Science, Faculty of Health, Queensland University of Technology, Kelvin Grove, QLD \\ 4059, Australia; james.broadbent@gmail.com \\ 4 Skin Research Institute of Singapore, Agency for Science, Technology and Research, 8A Biomedical Grove, \\ Singapore 138648, Singapore \\ * Correspondence: d.leavesley@sris.a-star.edu.sg
}

Received: 20 January 2020; Accepted: 4 February 2020; Published: 8 February 2020

\begin{abstract}
Extracellular membrane vesicles (EVs) have emerged as potential candidates for diagnostics and therapeutics. We have previously reported that keratinocytes release three types of EVs into the extracellular environment. Importantly, those EVs contain a large number of microRNAs (miRNAs) as cargo. In this study, we examined the expression level of keratinocyte-derived EV miRNAs, their target genes and potential functions. Next generation sequencing results showed that over one hundred miRNAs in each EV subtype exhibited greater than 100 reads per million (RPM), indicating a relatively high abundance. Analysis of the miRNAs with the highest abundance revealed associations with different keratinocyte cell sources. For instance, hsa-miR-205 was associated with the HaCaT cells whereas hsa-miR-21, hsa-miR-203, hsa-miR-22 and hsa-miR-143 were associated with human primary dermal keratinocytes (PKCs). Additionally, functional annotation analysis of genes regulated by those miRNAs, especially with regard to biological processes, also revealed cell-type-specific associations with either HaCaTs or PKCs. Indeed, EV functional effects were related to their parental cellular origin; specifically, PKC-derived EVs influenced fibroblast migration whereas HaCaT-derived EVs did not. In addition, the data in this current study indicates that keratinocyte-derived EVs and/or their cargoes have potential applications for wound healing.
\end{abstract}

Keywords: microRNA; extracellular membrane vesicle; keratinocytes; wound healing

\section{Introduction}

Keratinocytes are the predominant cell type in skin, which has the primary role to protect the body from environmental damage. Keratinocytes, including the HaCaT cell line and Primary Keratinocyte Cells (PKCs), are known to release EVs into the extracellular environment [1-3]. EVs are nanoscale particles ranging from $30 \mathrm{~nm}$ to $5000 \mathrm{~nm}$ in diameter that are released from various cell types [4]. EVs are classified into three categories, including apoptotic bodies (APs, 1-5 $\mu \mathrm{m}$ ), shedding microvesicles (MVs, 100-1000 nm) and exosomes (EXs, 30-150 nm) [5]. These three EV types are products of different biological processes; for instance, APs are products of apoptosis; MVs, also known as "ectosomes", are shed directly from the cellular membrane; and EXs are products of endocytosis, and re-release into the 
extracellular environment by exocytosis [5]. Importantly, evidence suggests that EVs have roles in many biological processes, such as tissue repair, embryonic development, pregnancy, immune response, cancer development and various others [6]. For example, EVs have been implicated in cutaneous wound healing processes through their influence on coagulation, angiogenesis, cell migration, cell proliferation and ECM production [7]. As such, understanding the molecular cargo of EVs released from keratinocytes is pivotal to enable further investigation of EV function.

Genetic molecules, including microRNAs (miRNAs), messenger RNAs (mRNAs) and DNA, have been discovered in EVs [7,8] According to Vesiclepedia, at least 10,520 EV miRNA molecules have been detected and identified (http://microvesicles.org/, v3.1, released 15/8/2018). miRNAs are small non-coding RNAs, 22-25 nucleotides in length and which function to regulate the translation of mRNAs by binding to their $3^{\prime}$ untranslated region [9]. The key concept in support of EV miRNAs is that these genetic molecules are delivered by EVs from parental cells to recipient cells $[8,10]$ where they might suppress or regulate gene expression post-transcriptionally, leading to changes in recipient cell behaviour. For example, mesenchymal stem cell-derived exosomes were found to transfer miRNA-125a to endothelial cells, which suppressed the production of angiogenic inhibitor delta-like 4 and thereby promoted the formation of endothelial tip cells and modulation of angiogenesis [10].

Despite there having been several investigations of EVs released from keratinocytes [1-3,11], there are only two publications describing EV miRNAs derived from keratinocytes [3,12]. Thus, there remains a lack of knowledge about keratinocyte-derived EV miRNAs and their involvement in skin physiology and pathology. In this study we present data obtained from the analysis of the miRNA profiles from the three EV populations isolated from $\mathrm{HaCaT}$ and PKCs. Our analysis revealed that the EV miRNA component is parental-cell specific and suggested that the EVs from different parental cells might elicit different functions on recipient cells. For example, we report that keratinocyte-derived EVs promoted the migration of human primary dermal fibroblasts in a cell-type-dependent manner.

\section{Results}

\subsection{HaCaT-and PKC-Derived EVs Exhibit Common Highly Abundant miRNAs}

The utilisation of deep-sequencing technology resulted in the identification of hundreds of EV-derived miRNAs. While the determination of whether all confer bioactivity is an important question, one previous study suggested that only highly abundant miRNAs have sufficient competitiveness for the miRNA-mRNA interaction to significantly suppress their targets [13]. Thus, in an attempt to better understand which populations of EV miRNAs might elicit substantial bioactivity, an analysis of the miRNA abundance (represented by total read count number) within each EV population was conducted. There were 181, 186 and 189 miRNAs with greater than 100 Reads Per Million (RPM) and 78, 78 and 69 miRNAs with greater than 1000 RPM from HaCaT-derived APs, MVs and EXs, respectively (Table 1). With regard to PKC-derived EVs, there were 210, 214 and 210 miRNAs that exhibited greater than 100 RPM and 82, 81 and 79 miRNAs having greater than 1000 RPM in APs, MVs and EXs, respectively (Table 1). Thus, it may be hypothesised that these highly abundant miRNAs confer detectable bioactivity and elicit functional responses in other cells and tissues.

Table 1. Number of highly abundant extracellular membrane vesicle (EV) miRNAs with reads per million (RPM) greater than 100 and greater than 1000.

\begin{tabular}{ccccc}
\hline Parental Cell Types & & AP & MV & EX \\
\hline \multirow{2}{*}{ HaCaT } & $>100$ RPM & 181 & 186 & 189 \\
& $>1000$ RPM & 78 & 78 & 69 \\
\hline \multirow{2}{*}{ Primary keratinocytes } & $>100 \mathrm{RPM}$ & 210 & 214 & 210 \\
& $>1000 \mathrm{RPM}$ & 82 & 81 & 79 \\
\hline
\end{tabular}


These data also showed that the majority of the five most abundant miRNAs were common to all EV released from both cell types, including hsa-miR-21, hsa-miR-22 and hsa-miR-27b (Table 2). Further the most abundant miRNAs that exhibited specificity with cellular origin, included hsa-miR-205 in HaCaT-derived EVs $(p<0.001)$ and hsa-miR-203 from PKC-derived EVs $(p<0.001)$. In addition, hsa-miR-181 was in the top five most abundant miRNA in HaCaT-derived APs and MVs, whereas hsa-miR-92 was in the top five most abundant miRNA in HaCaT-derived EXs (Table 2). With regard to PKC-derived EVs, hsa-miR-143 was in the top five most abundant in APs and MVs but did not rank in the PKC-derived EXs, whereas hsa-miR-205 was in the top five most abundant in the PKC-derived EX population but not in the top five most abundant miRNAs of APs and MVs released by PKCs (Table 2). Taken together these data indicate that the three EV populations from both keratinocyte cell types are largely enriched with the same miRNAs, which potentially suggest that the majority of miRNA mediated bioactivities of HaCaT- and PKC-derived EVs might also be the same.

Table 2. The relative abundance levels of the five most abundant miRNAs from HaCaT and primary keratinocyte-derived EVs.

\begin{tabular}{|c|c|c|c|c|c|}
\hline \multicolumn{6}{|c|}{ HaCaT } \\
\hline \multicolumn{2}{|r|}{ AP } & \multicolumn{2}{|r|}{ MV } & \multicolumn{2}{|r|}{ EX } \\
\hline miRNA Name & MN Counts \pm SD & miRNA Name & MN Counts \pm SD & miRNA Name & MN Counts \pm SD \\
\hline hsa-miR-205-5p & $106,506.6 \pm 8267.9^{* * * *}$ & hsa-miR-205-5p & $123,329.2 \pm 44,355.9^{* * *}$ & hsa-miR-205-5p & $100,832.8 \pm 16,630.3^{*}$ \\
\hline hsa-miR-22-3p & $92,576.7 \pm 16,680^{* * * *}$ & hsa-miR-27b-3p & $60,380.3 \pm 11,723.7^{* *}$ & hsa-miR-22-3p & $77,505.6 \pm 14,611.1 *$ \\
\hline hsa-miR-27b-3p & $57,661.6 \pm 7889.6^{* * * *}$ & hsa-miR-22-3p & $59,791.6 \pm 4818.9 * *$ & hsa-miR-27b-3p & $51,490.9 \pm 237.7^{* * *}$ \\
\hline hsa-miR-21-5p & $49,946.5 \pm 6634.3^{* * * * *}$ & hsa-miR-21-5p & $45,496.7 \pm 3357 * * *$ & hsa-miR-21-5p & $49,943.9 \pm 4831.5^{* * *}$ \\
\hline hsa-miR-181a-1-5p & $48,805.9 \pm 1721.1^{* * * * *}$ & hsa-miR-181a-1-5p & $45,541.5 \pm 3393.9^{* * *}$ & hsa-miR-92a-1-3p & $37,858.4 \pm 523.1 * * * *$ \\
\hline \multicolumn{6}{|c|}{ Primary Keratinocytes } \\
\hline \multicolumn{2}{|r|}{$\mathbf{A P}$} & \multicolumn{2}{|r|}{ MV } & \multicolumn{2}{|r|}{ EX } \\
\hline miRNA Name & MN Counts \pm SD & miRNA Name & MN Counts \pm SD & miRNA Name & MN Counts \pm SD \\
\hline hsa-miR-22-3p & $139,339.8 \pm 43,597.7^{* * *}$ & hsa-miR-22-3p & $93,878.6 \pm 29,984.7^{* * *}$ & hsa-miR-22-3p & $111,055.9 \pm 9430.8^{* * * * * *}$ \\
\hline hsa-miR-21-5p & $81,954.5 \pm 31,594.6$ & hsa-miR-21-5p & $86,901.3 \pm 21,422.5$ & hsa-miR-21-5p & $110,112.7 \pm 15,649.5$ \\
\hline hsa-miR-143-3p & $42,915.2 \pm 24,838.4 * *$ & hsa-miR-143-3p & $38,016.7 \pm 17,012.7^{* *}$ & hsa-miR-27b-3p & $52,399.1 \pm 8430.5^{* * * *}$ \\
\hline hsa-miR-203a-3p & $40,830.8 \pm 7053.9 * *$ & hsa-miR-27b-3p & $45,115.2 \pm 3168.5$ * & hsa-miR-203a-3p & $49,640.4 \pm 10,579.5^{* * * *}$ \\
\hline hsa-miR-27b-3p & $40,707.7 \pm 12,724.9^{* *}$ & hsa-miR-203a-3p & $34,067.1 \pm 13,381.3^{* *}$ & hsa-miR-205-5p & $44,981.6 \pm 10,617.4^{* * * * *}$ \\
\hline
\end{tabular}

MN counts: Mean of normalised read counts from biological repeats using the RPM method. RPM: Read Per Million. SD: Standard Deviation. Statistical significance was determined by ANOVA and Post-hoc Tukey HSD tests, and is indicated by * where $p<0.05$; ${ }^{* *}$ where $p<0.01$; ${ }^{* * *}$ where $p<0.001$; ${ }^{* * * *}$ where $p<0.0001$; ${ }^{* * * * *}$ where $p<0.00001$; $* * * * * *$ where $p<0.000001$.

\subsection{Specific EV miRNAs Are Correlated with Cellular Origin}

In order to determine whether the identified miRNAs explained the difference between the EVs of each parental cell line, the read count of identified miRNAs was analysed using principal component analysis (PCA). Loadings plots indicated that the majority of identified miRNAs did not substantially affect the difference between EV types from each parental cell type. hsa-miR-21, hsa-miR-203, hsa-miR-22 and hsa-miR-143 exhibited eigenvectors that were associated with PKCs in all three EV types while the hsa-miR-205 eigenvector was more strongly associated with $\mathrm{HaCaT}$ cells across all EV types (Figure 1). These miRNAs also exhibited the highest RPMs as reported in Table 2; thus, the PCA data was largely consistent with the RPM analysis suggesting that the relative abundance of these specific miRNAs is related to the cell type of origin. 

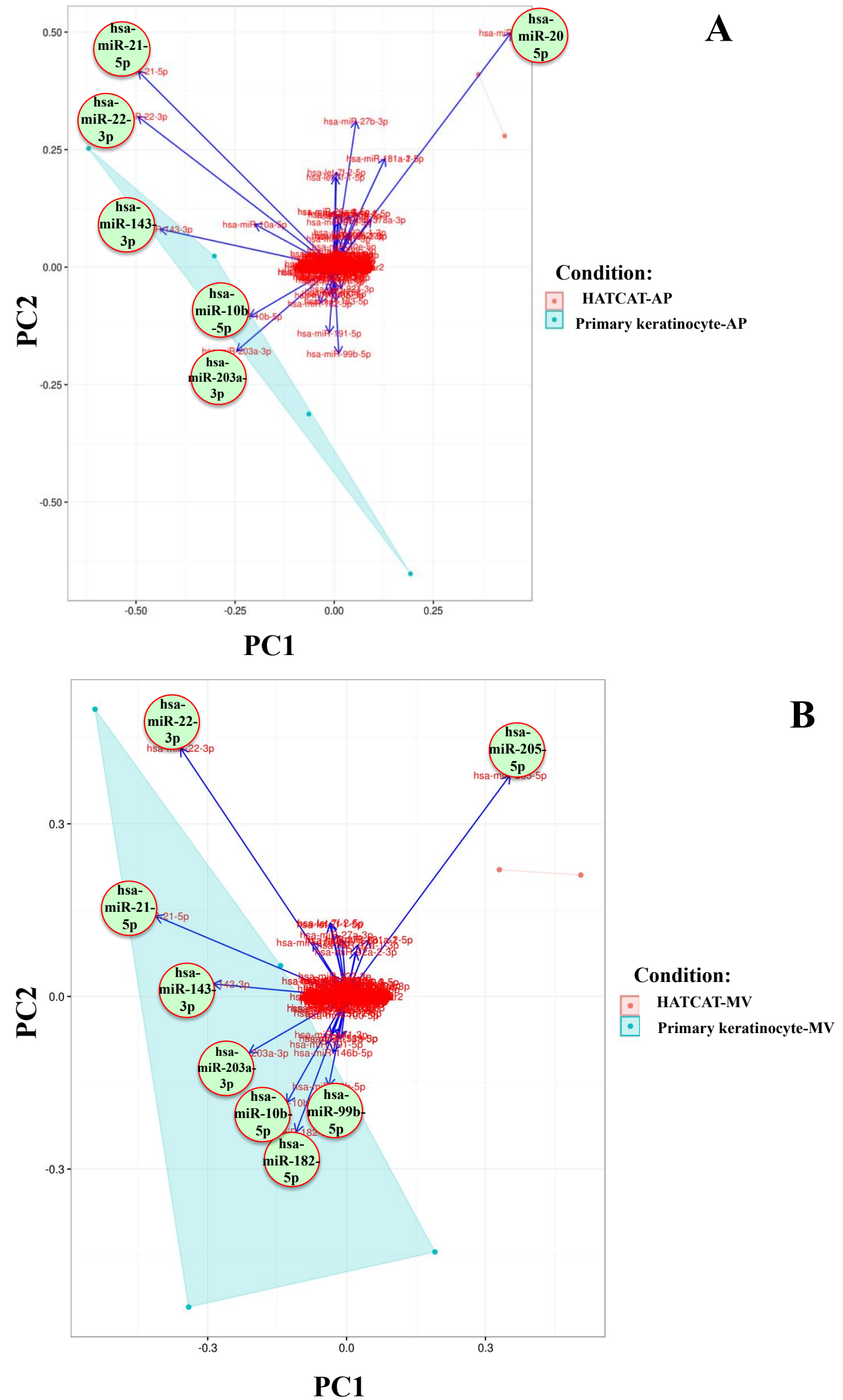

Figure 1. Cont. 


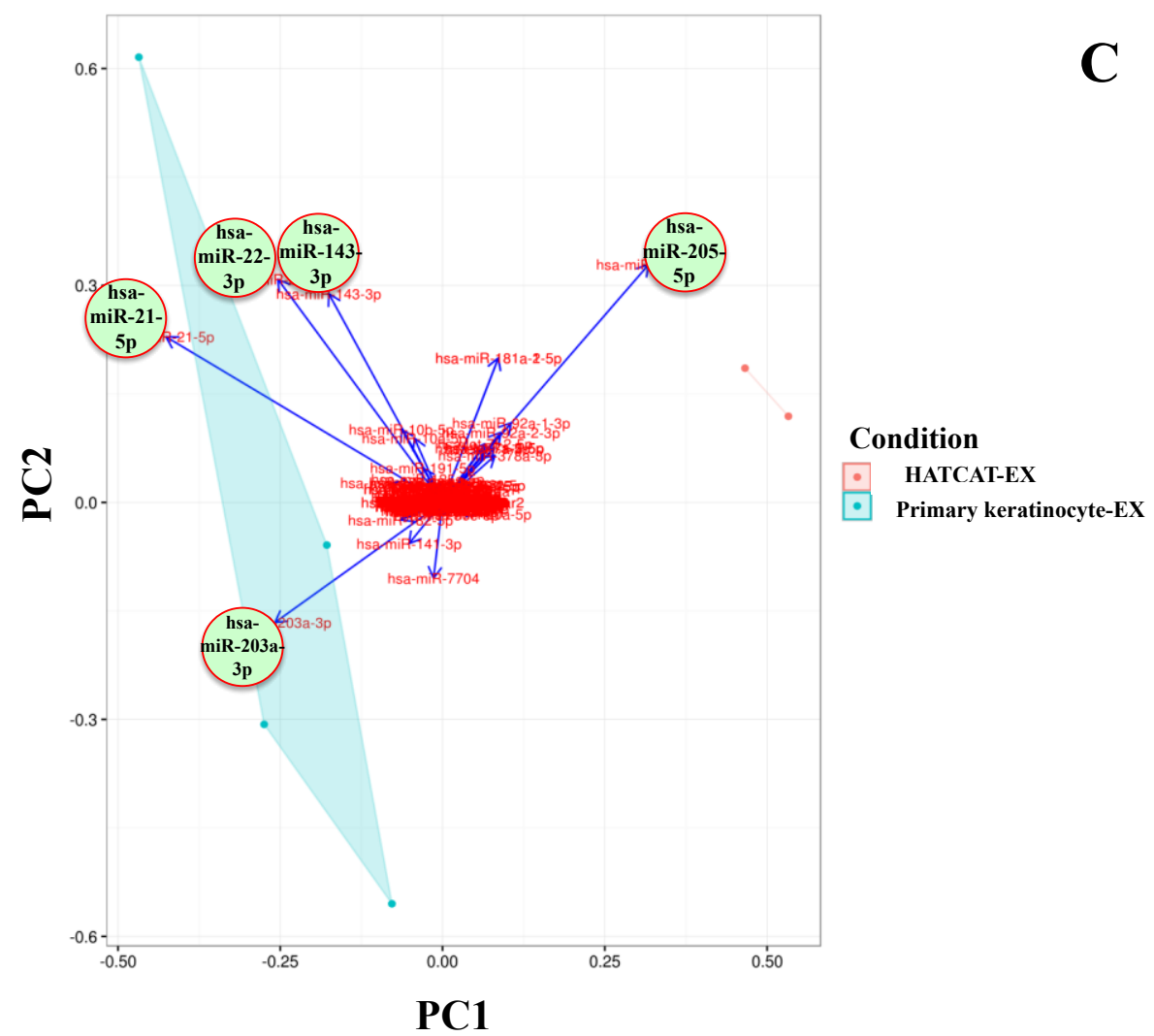

Figure 1. miRNA-205 is more associated with HaCaT cells and miRNA-21, miRNA-203, miRNA-22 and miRNA-143 are more associated with PKCs. Identified miRNAs from: (A) APs; (B) MVs; and (C) EXs. Biological replicates for HaCaT $(n=2)$ and PKCs $(n=4)$.

Upon closer examination, while hsa-miR-205 was most associated with all three HaCaT-derived EV types (Figure 1A-C), hsa-miR-21, hsa-miR-22, hsa-miR-143, hsa-miR-203, hsa-miR-10b and hsa-miR-205 exhibited the greatest eigenvector values in the PKC-derived AP populations (Figure 1A). Similarly, the eigenvectors of hsa-miR-22, hsa-miR-21, hsa-miR-143, hsa-miR-203, hsa-miR-10b, hsa-miR-182 and hsa-miR-99b were most strongly associated with differentiation of the PKC-derived MV population (Figure 1B). Interestingly, only hsa-miR-21, hsa-miR-203, hsa-miR-22 and hsa-miR-143 exhibited eigenvectors that were more associated with PKC-derived EXs; indeed, only these four miRNAs were common to all PKC-derived EVs (Figure 1C). Thus, these EV miRNAs appeared to be the most responsible for differentiating between PKC-derived and HaCaT-derived EVs. As such they were subjected to bioinformatics analysis to determine their potential target genes and therefore their potential bioactivities.

\subsection{Many Target Genes Regulated by miRNAs Associated with HaCaT and PKCs}

In order to investigate the potential difference in bioactivity of EVs derived from each parental cell type, EV miRNAs were analysed for their known target genes using miRTarbase20. The results indicated that hsa-miR-205 is known to regulate 168 target genes (which encoded for 173 proteins) (Figure 2A; Supplementary Table S1), while collectively the four miRNAs, hsa-miR-21, hsa-miR-203, hsa-miR-22 and hsa-miR-143, are known to regulate 1076 genes (encoding for 1098 proteins) (Figure 2B; Supplementary Table S2). 
A

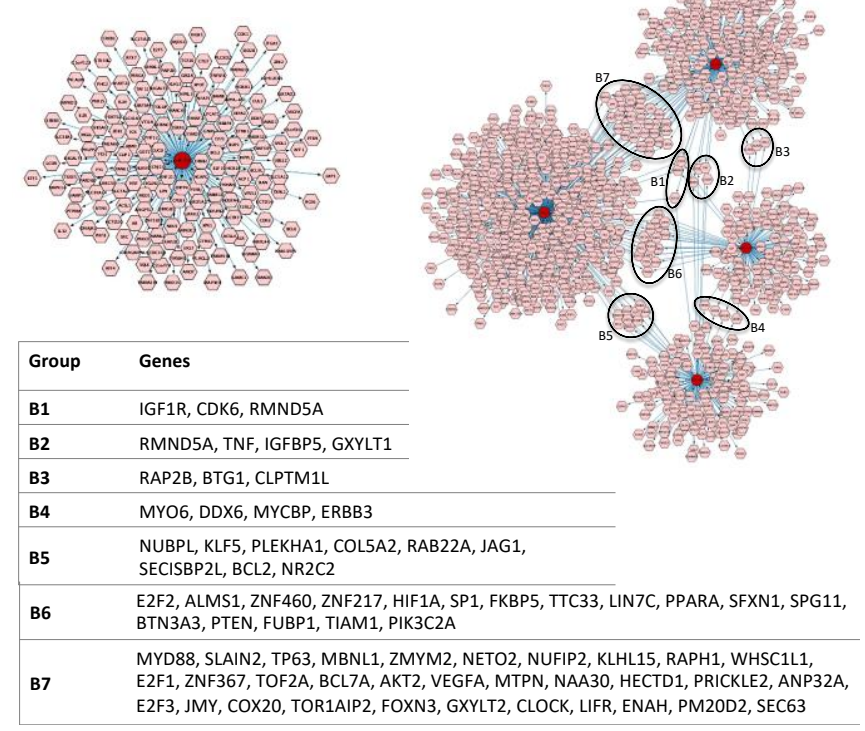

Figure 2. Network of target genes regulated by (A) hsa-miR-205 and (B) by a group of four miRNAs, including hsa-miR-21, hsa-miR-203, hsa-miR-22 and hsa-miR-143. Inset table indicates gene groupings regulated by at least (B1) three or (B2-B7) two miRNAs.

In order to organise these large sets of target genes into functionally related groups, they were further analysed using a Functional Classification Tool (DAVID Bioinformatics Resources v6.8). There were three functional groups classified from the target genes regulated by hsa-miR-205. The first group (enrichment score 2.72) is involved in protein kinase activity, cytoplasm, nucleus, membrane, metal, ATP and nucleotide binding. The second functional group (enrichment score 2.01) is involved in the zinc finger, nucleic acid/DNA/metal binding, repressor, activator, transcription and nucleus. Finally, the third group (enrichment score 1.08) is related to the plasma membrane, component of membrane, transmembrane, topological domain: cytoplasmic/extracellular, blood coagulation and haemostasis (Table 3). This suggests that HaCaT-derived vesicles are involved in those activities of binding, membrane, nucleus and haemostasis through hsa-miR-205.

Table 3. Functional classification of genes regulated by hsa-miR-205.

\begin{tabular}{ccc}
\hline Group (Enrichment Score) & Genes & Biological Function \\
\hline Group 1 (2.72) & MAP3K9, NEK9, ICK, STK38L & $\begin{array}{c}\text { Protein kinase, protein } \\
\text { phosphorylation, binding, nucleus, } \\
\text { cytosol, cytoplasm, membrane }\end{array}$ \\
\hline Group 2 (2.01) & BCL6, ZEB1, ZRB2, YY1, PLAGL2 & $\begin{array}{c}\text { Zinc finger, zinc, repressor, } \\
\text { activator, transcription, binding, } \\
\text { nucleus }\end{array}$ \\
& SLC38A1, TMEM123, PAPPA-AS1, & F2RL2, ENPP4, MMD, LYMSMD3, \\
SLC5A12, SHISA6, NIPA2, & $\begin{array}{c}\text { Plasma membrane, } \\
\text { transmembrane, topological } \\
\text { TM9SF2, LRRTM4, SLC39A14, } \\
\text { domain: cytoplasmic, topological } \\
\text { domain: extracellular, blood } \\
\text { coagulation and haemostasis }\end{array}$ \\
\hline
\end{tabular}

Additionally, 36 functional groups were classified from the target genes regulated by the four miRNAs associated with PKCs (Table 4). The highest ranked group was related to cytoplasm, nucleus, protein binding and phosphoprotein (enrichment score 27.64). The next group was associated with transcription, nucleus, protein binding, DNA binding and phosphoprotein (enrichment group 
score 19.96). However, the most common biological functions that appeared in all 36 classified groups included those involved in the nucleus, membrane, cytoplasm, binding activity and zinc finger. Additionally, others such as phosphoprotein, signalling pathway, transcription, kinase activity, transmembrane, cytosol and transport are the second most common biological functions that appeared in all functional groups (Table 4). This information indicates that PCK-derived EV miRNAs may participate in regulating biological processes at the nucleus, cytoplasm and membrane; for example, activities of phosphorylation, kinase and binding.

Table 4. Functional classification of genes regulated by a group of four miRNAs, including hsa-miR-21, hsa-miR-203, hsa-miR-22 and hsa-miR-143, which are highly correlated with PKCs.

\begin{tabular}{|c|c|c|}
\hline Group (Enrichment Score) & Genes & Biological Function \\
\hline Group 1 (27.64) & $\begin{array}{c}\text { PLEKHA2, NUDCD1, ELP5, FILIP1L, NUFIP2, } \\
\text { SERBP1, SSFA2, DAZAP2, HYPK, MYCBP, TSC22D4 }\end{array}$ & $\begin{array}{l}\text { Cytoplasm, nucleus, protein } \\
\text { binding, phosphoprotein }\end{array}$ \\
\hline Group 2 (19.96) & $\begin{array}{c}\text { ZBTB44, FAM208A, FOXK2, VGLL4, ZBTB8A, } \\
\text { MAFK, MGA, LRRFIP1, MED9, NFAT5, ZNF654, } \\
\text { ARID3B, MYCBP, HEXIM1, FOXN3, TAF1D, ATF7IP, } \\
\text { DNTTIP2, CSRNP2, MIER3, NFYB, NFYA, ANP32A, } \\
\text { FUBP1, ZNF646, TRAPPC2, PCGF6, ZNF367, NFIC, } \\
\text { LCORL, TCEAL1, ELP5, HOMEZ, NFIA, BTF3, } \\
\text { TSC22D4, SERTAD3, FOXN2, PURB, MACC1, PURA, } \\
\text { FOXK1, HMGB3, DMTF1, COMMD2, PHTF1, SOX5, } \\
\text { LCOR }\end{array}$ & $\begin{array}{l}\text { Transcription, nucleus, protein } \\
\text { binding, DNA binding, } \\
\text { phosphoprotein }\end{array}$ \\
\hline Group 3 (13.56) & $\begin{array}{l}\text { BUB1B, LATS1, CSNK1A1, RPS6KA3, SGK3, LIMK1, } \\
\text { IRAK1, PRKCE, CDK6, TESK2, DYRK3, MAP3K1, } \\
\text { WNK3, MAP3K2, WNK1, ROCK2, MAP3K7, CDKL2, } \\
\text { CIT, ACVR1C, CDK19, SLK, MAP2K3, SNRK, PIM3, } \\
\text { SRPK2, SRPK1, MAP3K13, HIPK3, PDIK1L, MAPK7, } \\
\text { MKNK2, NEK1, FRK, CSNK2A1 }\end{array}$ & $\begin{array}{l}\text { Kinase activity, transferase, } \\
\text { phosphoprotein, binding } \\
\text { (protein, ATP, nucleotide), } \\
\text { cytoplasm, nucleus, cytosol, } \\
\text { protein phosphorylation, } \\
\text { proton receptor }\end{array}$ \\
\hline Group 4 (11.94) & TGIF1, HOMEZ, ZEB2, SATB1 & $\begin{array}{l}\text { Transcription activity, nucleus, } \\
\text { binding, acetylation, } \\
\text { homeobox, phosphoprotein, } \\
\text { repressor }\end{array}$ \\
\hline Group 5 (11.74) & $\begin{array}{l}\text { RAPH1, OSBPL3, PLEKHA8, SKAP2, EXOC8, OSBP, } \\
\text { SPATA13 }\end{array}$ & $\begin{array}{c}\text { Membrane, transport, cytosol, } \\
\text { cytoplasm, protein binding, } \\
\text { pleckstrin homology, } \\
\text { phosphoprotein }\end{array}$ \\
\hline Group 6 (11.44) & $\begin{array}{l}\text { RLIM, RNF103, TRIM38, BMI1, RFFL, UBR3, RNF6, } \\
\text { TRIM33, TRIM59, RNF185, PCGF6, RNF111, } \\
\text { MARCH3, CBLL1, RNF11, DTX3L, RSPRY1, } \\
\text { TOPORS, TRIM4, TRIM2, RNF141, SCAF11, MYCBP2 }\end{array}$ & $\begin{array}{l}\text { Zinc, zinc finger, binding } \\
\text { (metal, protein, ion), ligase } \\
\text { activity, phosphoprotein, } \\
\text { nucleus, Ubl conjugation } \\
\text { pathway, RING }\end{array}$ \\
\hline Group 7 (11.15) & $\begin{array}{l}\text { NCL, CPEB4, RBM27, MYEF2, MSI2, ELAVL4, } \\
\text { RBM39, SREK1, SRSF7, HNRNPH1, CPEB3, CELF2, } \\
\text { PTBP3, PPIL4, HNRNPA3, SRSF11, HNRNPR }\end{array}$ & $\begin{array}{c}\text { RNA/nucleotide/nucleic } \\
\text { binding, protein binding, } \\
\text { nucleus, cytoplasm, } \\
\text { acetylation, mRNA processing, } \\
\text { nucleoplasm }\end{array}$ \\
\hline Group 8 (9.92) & ZMAT5, MBNL1, SNRNP48, SCAF11 & $\begin{array}{l}\text { Spliceosome, metal/zinc/ion } \\
\text { binding, protein binding, } \\
\text { nucleus, cytoplasm, RNA } \\
\text { binding, RNA splicing, mRNA } \\
\text { processing, phosphoprotein, } \\
\text { zinc finger }\end{array}$ \\
\hline
\end{tabular}


Table 4. Cont.

\begin{tabular}{|c|c|c|}
\hline Group (Enrichment Score) & Genes & Biological Function \\
\hline Group 9 (9.74) & $\begin{array}{c}\text { ZNF667, RSF1, ZBTB44, ZBTB8A, PHF20L1, } \\
\text { WHSC1L1, ZNF662, ZBTB47, REST, ZNF654, ZNF35, } \\
\text { ZNF587, ZNF326, ZNF573, ZNF704, ZNF217, ARID2, } \\
\text { ZNF429, ZNF24, RREB1, ZNF277, ZNF207, SNAI1, } \\
\text { ZNF268, ZNF460, NR2C2, ZNF200, ZEB2, ZUFSP, } \\
\text { SUZ12, ZNF292, TSHZ3, THAP1, SNAI2, ZNF646, } \\
\text { ZNF607, HIC2, BCL11B, ZNF652, BCL6, ZNF367, } \\
\text { PCGF6, KAT7, GLIS3, ATMIN, PHF20, ADNP, KLF5, } \\
\text { KLF9, ZNF264, SP1, GLIS2, KAT6A, ZBTB20, } \\
\text { ZNF148, ZNF532, TRPS1, TRIM33, BAZ1B, IKZF3, } \\
\text { ZNF451, ZNF440, LCOR, ZBTB38, ZEB1 }\end{array}$ & $\begin{array}{l}\text { Zinc finger, zinc, nucleus, } \\
\text { transcription, binding (meta, } \\
\text { protein, ion, DNA, nucleic } \\
\text { acid), phosphoprotein }\end{array}$ \\
\hline Group 10 (9.29) & USP7, USP47, USP42, USP34 & $\begin{array}{c}\text { Cytosol, cytoplasm, nucleus, } \\
\text { DNA repair, ubiquitin activity, } \\
\text { protease, hydrolase, } \\
\text { phosphoprotein, acetylation }\end{array}$ \\
\hline Group 11 (9.13) & NR2C2, ESR1, PPARA, NR2F2, NR3C1, HNF4A & $\begin{array}{c}\text { Regulation of transcription, } \\
\text { acetylation, cytoplasm, } \\
\text { nucleus, } \\
\text { protein/metal/DNA/ion } \\
\text { binding, receptor, lipid } \\
\text { metabolic process, activator, } \\
\text { phosphoroprotein, disease } \\
\text { mutation, nucleoplasm }\end{array}$ \\
\hline Group $12(8.74)$ & SMAD2, SMAD3, SMAD4, SMAD7, SMAD9 & $\begin{array}{l}\text { Signalling pathway, binding, } \\
\text { cell cycle, transcription, } \\
\text { nucleus, cytoplasm, cancer, } \\
\text { disease mutation }\end{array}$ \\
\hline Group 13 (8.55) & $\begin{array}{l}\text { RPS4X, RPS7, RPS19, RPS27, RPS2, RPL35A, RPSA, } \\
\text { RPL24 }\end{array}$ & $\begin{array}{l}\text { Nucleus, cytoplasm, } \\
\text { phosphoprotein, extracellular } \\
\text { matrix, binding translation, } \\
\text { ribonucleoprotein, ribosomal } \\
\text { protein, membrane, cytosol, } \\
\text { exosome }\end{array}$ \\
\hline Group 14 (8.54) & $\begin{array}{l}\text { DDX3X, EIF4A2, SMARCA4, DHX33, ATRX, DDX46, } \\
\text { DDX55, DDX3Y, CHD9, DDX6 }\end{array}$ & $\begin{array}{l}\text { Cytoplasm, nucleus, binding, } \\
\text { phosphoprotein, helicase, } \\
\text { hydrolase, ubl conjugation }\end{array}$ \\
\hline Group 15 (8.26) & TTC38, TTC33, SGTB, FKBP5 & $\begin{array}{l}\text { Extracellular exosome, } \\
\text { chaperone, acetylation, } \\
\text { phosphoprotein, } \\
\text { tetratricopeptide, protein } \\
\text { binding }\end{array}$ \\
\hline Group 16 (7.89) & $\begin{array}{l}\text { TGIF1, MEIS1, HOXA1, EN2, PBX1, HOXA9, } \\
\text { PKNOX1 }\end{array}$ & $\begin{array}{c}\text { Transcription, DNA binding, } \\
\text { organism development, } \\
\text { homeobox, nucleus }\end{array}$ \\
\hline Group 17 (7.74) & $\begin{array}{l}\text { ANKRD9, CLIP4, RAI14, SOWAHC, HECTD1, } \\
\text { ANKRD46, ANKRD13B }\end{array}$ & Phosphoprotein, Ankyrin \\
\hline Group 18 (7.74) & SETD2, WHSC1, WHSC1L1, TRIM33, SETD1B & $\begin{array}{c}\text { Transcription regulation, zinc } \\
\text { finger, chromosome, } \\
\text { transferase, nucleus, } \\
\text { phosphoprotein, isopeptide } \\
\text { bond, Ubl conjugation, } \\
\text { associated with SET domain }\end{array}$ \\
\hline Group 19 (7.00) & $\begin{array}{c}\text { ARHGEF28, FGD6, RALGPS2, NET1, SPATA13, } \\
\text { ARHGEF12 }\end{array}$ & $\begin{array}{l}\text { Cell membrane, cytosol, } \\
\text { cytoplasm, signal transduction, } \\
\text { Rho guanyl-nucleotide } \\
\text { exchange factor, } \\
\text { phosphoprotein }\end{array}$ \\
\hline
\end{tabular}


Table 4. Cont.

\begin{tabular}{|c|c|c|}
\hline Group (Enrichment Score) & Genes & Biological Function \\
\hline Group $20(6.74)$ & DOCK4, RALGPS2, DOCK7, DOCK10, DOCK5 & $\begin{array}{l}\text { Cytoplasm, cell membrane, } \\
\text { acetylation, dedicator of } \\
\text { cytokinesis, GTPase activity, } \\
\text { phosphoprotein, } \\
\text { DOCK-homology region, } \\
\text { intracellular }\end{array}$ \\
\hline Group 21 (6.48) & KIF13A, KIF5B, KIF1C, KIF2A, DYNC1LI2 & $\begin{array}{c}\text { Membrane, centrosome, } \\
\text { methylation, ATPase activity, } \\
\text { kinesin, cytoplasm, ATP } \\
\text { binding, cytoskeleton, coiled } \\
\text { coil, microtube }\end{array}$ \\
\hline Group $22(6.13)$ & $\begin{array}{c}\text { AKT2, PIK3CA, HRAS, AKT1, MAPK1, PIK3R1, } \\
\text { MAPK9, MAPK8 }\end{array}$ & $\begin{array}{c}\text { Signalling pathway (GnRH, } \\
\text { MAPKinase, EGF, PDGF, } \\
\text { IGF-1, insulin, CXCR4, Rrk, } \\
\text { PI3, ERBB2, Trka receptor, Ras, } \\
\text { Jak-STAT, AMPK, ErbB, cAMP, } \\
\text { Toll-line receptor), binding, } \\
\text { disease, cancer, cytosol, kinase } \\
\text { activity, nucleus, cytoplasm, } \\
\text { acetylation, infection, } \\
\text { apoptosis, }\end{array}$ \\
\hline Group 23 (5.99) & $\begin{array}{c}\text { BMPR2, BMPR1B, BMPR1A, TGFBR2, ACVR1C, } \\
\text { ACVR2B, DDR2 }\end{array}$ & $\begin{array}{c}\text { Phosphoprotein, } \\
\text { phosphorylation, kinase } \\
\text { activity, signalling pathway } \\
\text { (Hippo, BMP, regulation of } \\
\text { stem cell, TGF-beta), binding } \\
\text { (ATP, metal, nucleotide, ion, } \\
\text { protein) TGF-beta receptor, } \\
\text { phosphorylation, disease } \\
\text { mutation, disulphide bond, } \\
\text { transferase, receptor, } \\
\text { membrane, transmembrane, } \\
\text { signal, extracellular }\end{array}$ \\
\hline Group 24 (5.41) & $\begin{array}{l}\text { EGFR, PDGFRA, EPHA4, ERBB3, ERBB2, CSF1R, } \\
\text { DDR2, IGF1R }\end{array}$ & $\begin{array}{l}\text { Membrane, transmembrane, } \\
\text { receptor, signal, binding (ATP, } \\
\text { nucleotide, protein), kinase, } \\
\text { signalling pathway (Ras, Rap1, } \\
\text { calcium, cancer), wound } \\
\text { healing, cancer, endocytosis, } \\
\text { transferase, microRNAs in } \\
\text { cancer, cytoplasm, } \\
\text { phosphorylation activity, } \\
\text { glycoprotein, extracellular, } \\
\text { cytoplasm, disease mutation }\end{array}$ \\
\hline Group 25 (5.19) & RASGRP3, RALGPS2, RAPGEF6, RGL2 & $\begin{array}{c}\text { Cytoplasm, membrane, } \\
\text { signalling pathway (Ras, } \\
\text { Rap1,) binding (Ras GTPase, } \\
\text { protein) signal transduction, } \\
\text { GTPase activity, } \\
\text { phosphoprotein, Ras guanine } \\
\text { nucleotide exchange factor }\end{array}$ \\
\hline Group $26(4.74)$ & $\begin{array}{l}\text { STXBP5, WDR7, WSB1, CORO2A, DCAF10, WDR77, } \\
\text { PHIP, BRWD3, GNB4, NBEA, ELP2, DCAF8, FBXW7, } \\
\text { TBL1XR1, TAF5 }\end{array}$ & $\begin{array}{l}\mathrm{WD}(1,2,3,4,5,6,7,40), \mathrm{WD} \\
\text { repeat, phosphoprotein }\end{array}$ \\
\hline Group 27 (4.14) & DUSP5, PTPDC1, DUSP8, DUSP10 & $\begin{array}{c}\text { Phosphatase activity, } \\
\text { cytoplasm nucleus, } \\
\text { nucleoplasm, hydrolase, } \\
\text { MAPK signalling pathway, } \\
\text { Rhodanese, } \\
\text { dephosphorylation }\end{array}$ \\
\hline
\end{tabular}


Table 4. Cont.

\begin{tabular}{|c|c|c|}
\hline Group (Enrichment Score) & Genes & Biological Function \\
\hline Group 28 (3.49) & $\begin{array}{c}\text { RHOB, RAB6C, RHOQ, RAB22A, RAB33B, RAB6A, } \\
\text { RAB5B, RAP2B, RAB44 }\end{array}$ & $\begin{array}{c}\text { Cytosol, membrane, transport, } \\
\text { methylation, GTPase activity, } \\
\text { extracellular exosome, binding } \\
\text { (protein, nucleotide, GTP, } \\
\text { phosphate, lipid), lipoprotein, } \\
\text { prenylation }\end{array}$ \\
\hline Group 29 (3.12) & SOCS5, SOCS4, SOCS3, SOCS6 & $\begin{array}{l}\text { Protein binding, growth } \\
\text { regulation, regulation of } \\
\text { Jak-STAT, signal transduction } \\
\text { inhibitor, signalling pathway } \\
\text { (STAT, prolactin, } \\
\text { cytokine-mediated, insulin), } \\
\text { cytoplasm, SOCS box, SH2 } \\
\text { domain, Ubl conjugation } \\
\text { pathway, intracellular, } \\
\text { inflammation response, } \\
\text { suppressor of cytokine } \\
\text { signalling, type II diabetes } \\
\text { mellitus, protein } \\
\text { ubiquitination }\end{array}$ \\
\hline
\end{tabular}

Membrane, transmembrane, lipid metabolism, lipid

Group 30 (2.77) LCLAT1, SERINC1, SERAC1, LPGAT1, TMEM147 biosynthesis, phospholipid metabolism, phospholipid biosynthesis, protein binding, endoplasmic reticulum membrane

\begin{tabular}{cc}
\hline & \\
Group $31(2.73)$ & LRRC20, FBXL2, LRRC57, TBCEL, CEP97, SKP2, \\
FBXL5, VASN, FBXL13, FMOD, GP5, ZYG11B, \\
FBXL3, LRRC1, CNTRL, LRRC2
\end{tabular}

Leucine-rich repeat $(1,2,3,4,5$, $6,7,8)$, protein binding

Extracellular matrix, signal, disease mutation, extracellular region, fibrillar collagen, focal adhesion, collagen, secreted, binding (metal, ion,

Group 32 (2.57)

COL4A1, COL3A1, COL5A2, COL5A1, COL1A1 platelet-derived growth factor), PI3-Akt signalling pathway, calcium, glycoprotein, skin development, disulphide bond, glycosylation, skeletal system development

Kelch $(1,2,3,4,5,6)$, kelch repeat, kelch-like protein, protein

Group 33 (1.50)

IVNS1ABP, KLHL24, KBTBD6, KBTBD7, IPP, KLHL15, KLHL28 ubiquitination, ubiquitineous activity, BTB domain, $\mathrm{BTB} / \mathrm{POZ}$

Zinc, calcium, signal, membrane, extracellular matrix, collagen degradation, hemopexin-like domain, metallopeptidase,

Group 34 (1.25)

MMP13, PAPPA, MMP10, MMP9, ADAMTS4, MMP2, MMP1 glycoprotein, zymogen, protease, hydrolase, disulphide bond, metal binding

Transmembrane, metabolic pathway, sphingolipid activity, pyridoxal phosphate, endoplasmic reticulum, 
Table 4. Cont.

\begin{tabular}{|c|c|c|}
\hline Group (Enrichment Score) & Genes & Biological Function \\
\hline Group 36 (0.01) & $\begin{array}{l}\text { EDNRA, C15orf48, ARMCX3, VOPP1, ANKRD46, } \\
\text { TMPPE, SLC2A14, SACM1L, TMEM2, ST6GAL1, } \\
\text { FAM20B, SAMD5, SLC31A1, GLRA3, SLC12A5, } \\
\text { TMEM178B, BOC, SLC16A10, FGFRL1, TM9SF3, } \\
\text { IL13RA1, LIFR, B3GNT5, LMBR1, TMEM170A, } \\
\text { IL10RB, PIGX, GALNT6, CNNM3, SLC17A5, DSE, } \\
\text { SLC44A1, SGCB, SLC39A9, CERS6, FAXC, FAXDC2, } \\
\text { TMEM56, CHST10, TMED4, MCTP1, SLC26A2, } \\
\text { TMEM147, B3GALNT1, HTR2C, MRAP2, PGRMC2, } \\
\text { BSG, SFXN1, CADM2, SFT2D2, SLC45A4, COX20, } \\
\text { PEAR1, TOR1AIP2, CCR7, CCR6, CCR5, CCR1, } \\
\text { NCSTN, NETO2, HEPHL1, OR7D2, BTN3A3, GJD2, } \\
\text { CYBRD1, PIGN, LRIT3, CLPTM1L, MGAT4A, CDH7, } \\
\text { HERPUD2, MXRA7, TMEM245, MEGF9, GPR156, } \\
\text { SLMAP, PIGP, HSP40, GXYLT2, TMEM97, SLC5A3, } \\
\text { EXT1, MOXD1, SERINC1, SCN2B, CD151, HS3ST3B1, } \\
\text { GXYLT1, TNFRS10B, TMEM120B, ORAI2, OLR1, } \\
\text { TNFRSF10D, PTGFR, CD47, CD44, RER1 }\end{array}$ & $\begin{array}{c}\text { Membrane, transmembrane, } \\
\text { glycoprotein, cytoplasmic } \\
\text { domain, glycosylation }\end{array}$ \\
\hline
\end{tabular}

\subsection{Regulatory Roles of EVs}

In order to determine the potential biological processes (BPs) regulated by the target genes of the EV miRNA that were associated with HaCaT and PKCs (from Figure 2), a gene ontology (GO) analysis was performed using Cytoscape BiNGO (v3.2.1). The BP terms associated with the target genes regulated by hsa-miR-205, and therefore EVs derived from HaCaT cells, were mostly related to regulation, organ morphogenesis and development, metabolic processes, response to stimulus, transport and signalling pathways (Figure 3). Regarding the target genes regulated by the four miRNAs, which are highly enriched within PKCs, the BP analysis revealed that they were associated with regulation activity; response to stimulus; developmental process; metabolic process; protein transport and localisation; cellular component organization and apoptosis; and programmed cell death (Figure 4).

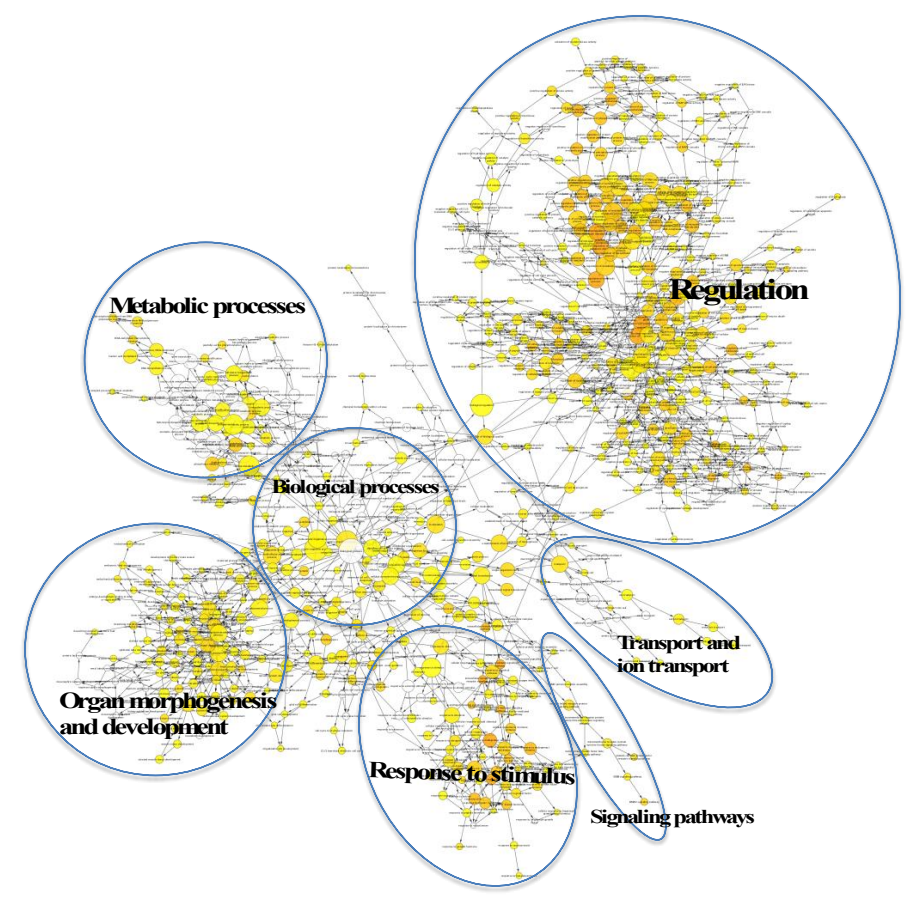

Figure 3. Visualisation of the biological processes (BPs) resulting from the analysis of target genes regulated by hsa-miR-205 associated with HaCaT-derived EVs using Cytoscape (Version 3.2.1). 


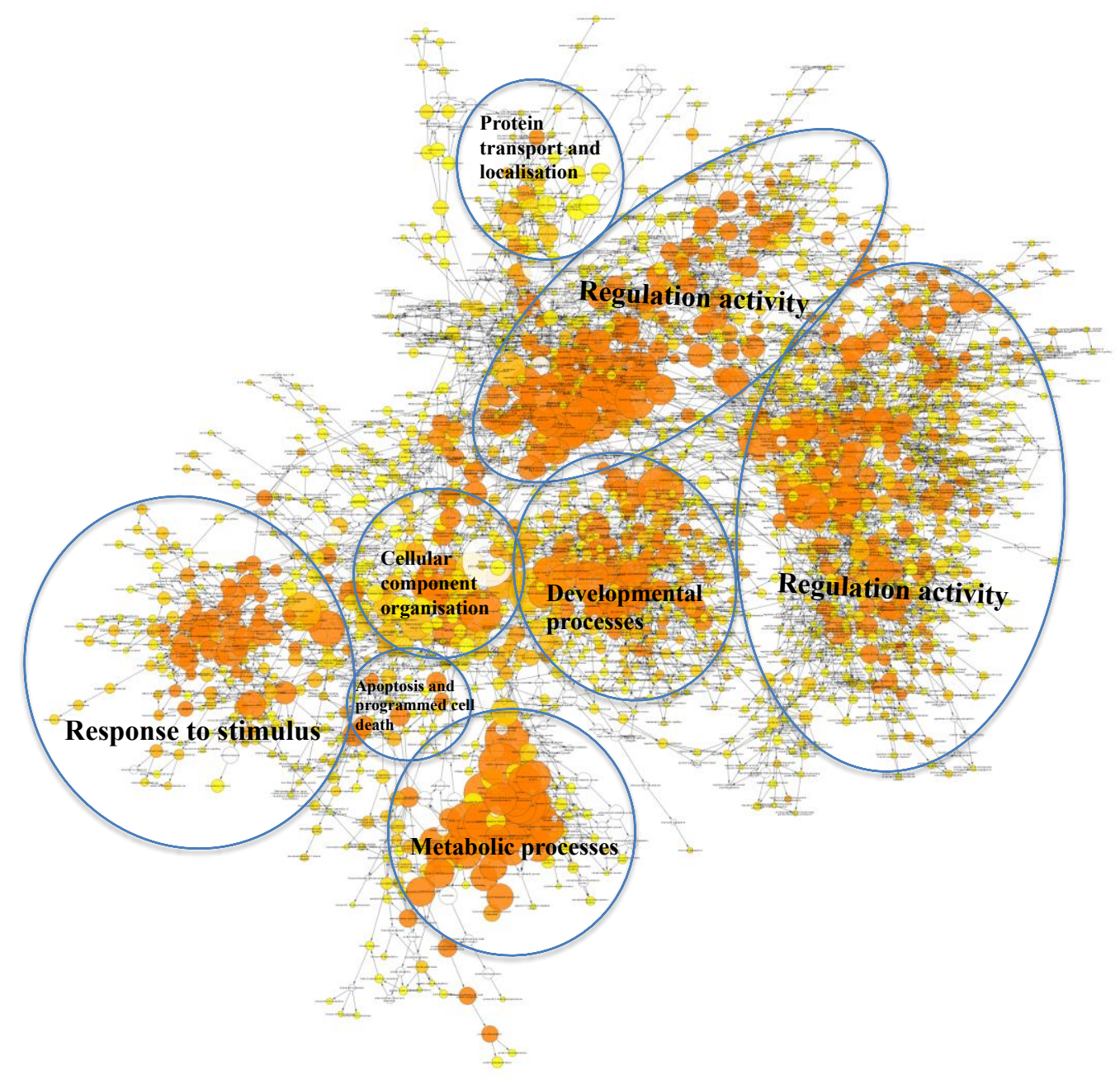

Figure 4. Visualisation of the BPs resulted from the analysis of target genes regulated by a group of four miRNAs (hsa-miR-21, hsa-miR-203, hsa-miR-22 and hsa-miR-143) associated with PKCs using Cytoscape (Version 3.2.1).

A report of the 20 most significantly over represented BP terms associated with the target genes of the highly abundant EV-derived miRNAs from HaCaT and PKCs revealed three common terms between the two cell types, including positive regulation of macromolecule metabolic process, positive regulation of cellular metabolic process and positive regulation of metabolic process. This indicates that these highly abundant EV miRNAs may impact recipient cell metabolic activity through regulation of the translation of their target genes. Interestingly, the unique terms overrepresented by the target genes of miRNA associated with HaCaT-derived EVs were linked to regulation of phosphorylation and steroid hormone pathways; in turn, the unique terms overrepresented by the target genes of miRNA associated with PKC-derived EVs were associated with metabolic processes, apoptosis and cell death (Figure 5, Supplemental Table S3). 


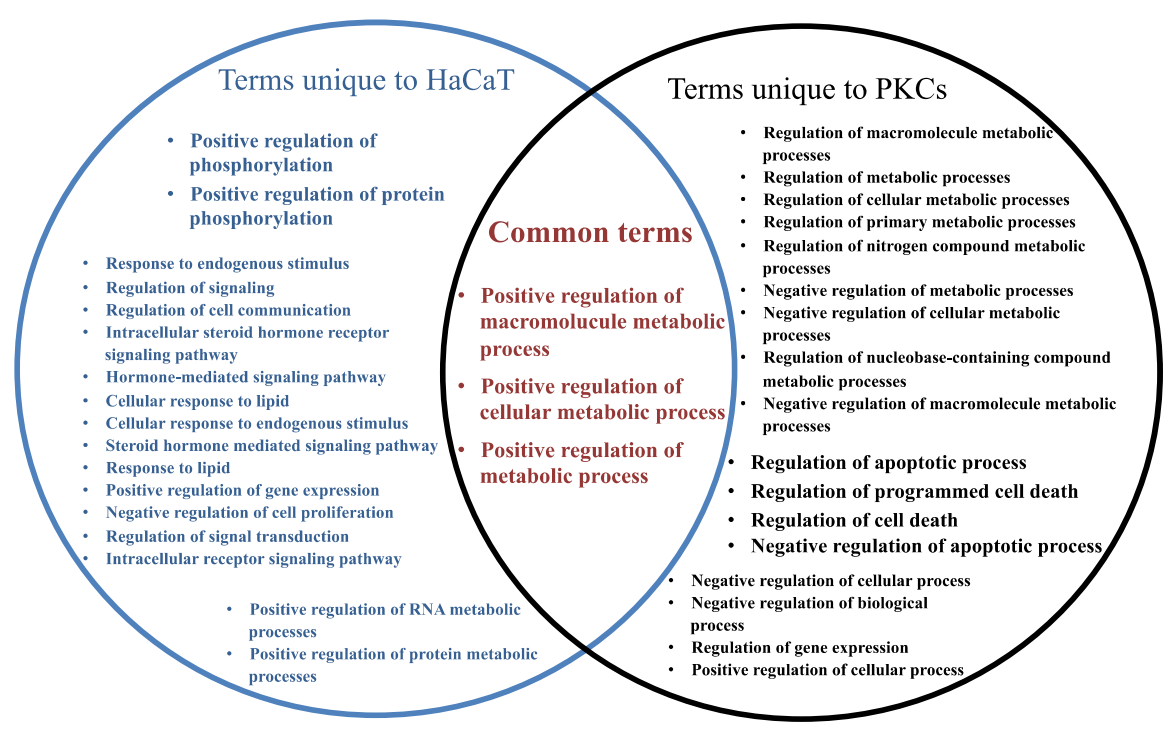

Figure 5. Common and unique terms associated with HaCaT- and PKC-derived EVs. The reported terms herein are from the 20 most statistically significant GO Terms. The red text indicates common terms associated with the target genes of miRNA from HaCaT- and PKC-derived EVs.

\subsection{Target Genes Regulated by EV miRNAs Related to Cell Migration}

In order to examine the association of keratinocyte-derived EVs with wound healing through fibroblast migration, we further analysed the obtained BP terms (from Figure 3 to Figure 4) to find any terms related to cell migration. The data revealed that that the target genes regulated by hsa-miR-205, which was associated with EVs derived from $\mathrm{HaCaT}$ cells, was enriched in six cell migration-related terms. In addition, the four miRNAs (hsa-miR-21, hsa-miR-203, hsa-miR-22 and hsa-miR-143) that were associated with PKC-derived EVs were enriched in 25 migration terms (Table 5). This suggests that EVs from both cell types may contribute to some extent in the regulation of cell migration. Importantly, the term "Regulation of fibroblast migration" was found to be enriched only in the PKC-derived EV miRNAs. 
Table 5. BP terms related to migration.

\begin{tabular}{|c|c|c|c|}
\hline Terms & $p$-adj & Terms & $p$-adj \\
\hline \multicolumn{4}{|c|}{ Target Genes Associated with HaCaT Cell-Derived EV miRNAs } \\
\hline Regulation of cell migration & 0.0033 & Epithelium migration & 0.0382 \\
\hline $\begin{array}{l}\text { Negative regulation of cell } \\
\text { migration }\end{array}$ & 0.0301 & $\begin{array}{l}\text { Regulation of epithelial cell } \\
\text { migration }\end{array}$ & 0.0398 \\
\hline Epithelial cell migration & 0.0352 & Tissue migration & 0.0465 \\
\hline \multicolumn{4}{|c|}{ Target Genes Associated with Primary Keratinocyte-Derived EV miRNAs } \\
\hline Regulation of cell migration & 0.0001 & $\begin{array}{l}\text { Regulation of mononuclear cell } \\
\text { migration }\end{array}$ & 0.0032 \\
\hline $\begin{array}{l}\text { Positive regulation of cell } \\
\text { migration }\end{array}$ & 0.0001 & $\begin{array}{l}\text { Regulation of vascular } \\
\text { associated smooth muscle cell } \\
\text { migration }\end{array}$ & 0.0063 \\
\hline $\begin{array}{l}\text { Positive regulation of epithelial } \\
\text { cell migration }\end{array}$ & 0.0001 & $\begin{array}{l}\text { Regulation of blood vessel } \\
\text { endothelial cell migration }\end{array}$ & 0.0088 \\
\hline $\begin{array}{l}\text { Regulation of epithelial cell } \\
\text { migration }\end{array}$ & 0.0001 & $\begin{array}{l}\text { Regulation of fibroblast } \\
\text { migration }\end{array}$ & 0.0092 \\
\hline $\begin{array}{l}\text { Positive regulation of } \\
\text { endothelial cell migration }\end{array}$ & 0.0001 & $\begin{array}{l}\text { Regulation of leukocyte } \\
\text { migration }\end{array}$ & 0.012 \\
\hline $\begin{array}{l}\text { Regulation of endothelial cell } \\
\text { migration }\end{array}$ & 0.0001 & $\begin{array}{l}\text { Positive regulation of vascular } \\
\text { associated smooth muscle cell } \\
\text { migration }\end{array}$ & 0.0161 \\
\hline Cell migration & 0.0001 & Leukocyte migration & 0.0169 \\
\hline $\begin{array}{l}\text { Positive regulation of } \\
\text { mononuclear cell migration }\end{array}$ & 0.0002 & Thymocyte migration & 0.0192 \\
\hline $\begin{array}{l}\text { Regulation of smooth muscle } \\
\text { cell migration }\end{array}$ & 0.0007 & $\begin{array}{l}\text { Positive regulation of fibroblast } \\
\text { migration }\end{array}$ & 0.0211 \\
\hline $\begin{array}{l}\text { Positive regulation of leukocyte } \\
\text { migration }\end{array}$ & 0.0011 & $\begin{array}{l}\text { Regulation of trophoblast cell } \\
\text { migration }\end{array}$ & 0.0411 \\
\hline $\begin{array}{l}\text { Negative regulation of cell } \\
\text { migration }\end{array}$ & 0.0011 & $\begin{array}{l}\text { Positive regulation of cell } \\
\text { migration involved in sprouting } \\
\text { angiogenesis }\end{array}$ & 0.0411 \\
\hline $\begin{array}{l}\text { Positive regulation of blood } \\
\text { vessel endothelial cell migration }\end{array}$ & 0.0017 & Dendritic cell migration & 0.0423 \\
\hline $\begin{array}{l}\text { Positive regulation of smooth } \\
\text { muscle cell migration }\end{array}$ & 0.0032 & & \\
\hline
\end{tabular}

We validated the influence of keratinocyte-derived EVs on human primary dermal fibroblast migration using a scratch wound assay created in a monolayer of dermal fibroblasts and subsequently treated with keratinocyte-derived EVs. We found that, in general, the migration of fibroblasts treated with HaCaT-derived EVs were indistinguishable to the untreated controls (Figure 6A,C,E). In contrast, observations of primary fibroblasts treated with PKC-derived EVs revealed that the fibroblasts generally migrated more in response to EV treatment and the extent of cell migration was dependent on EV types and doses (Figure 6B,D,F). This indicated that the capacity of EVs to enhance human dermal fibroblast migration depends on the EV cellular origin. 
HaCaT-derived EVs
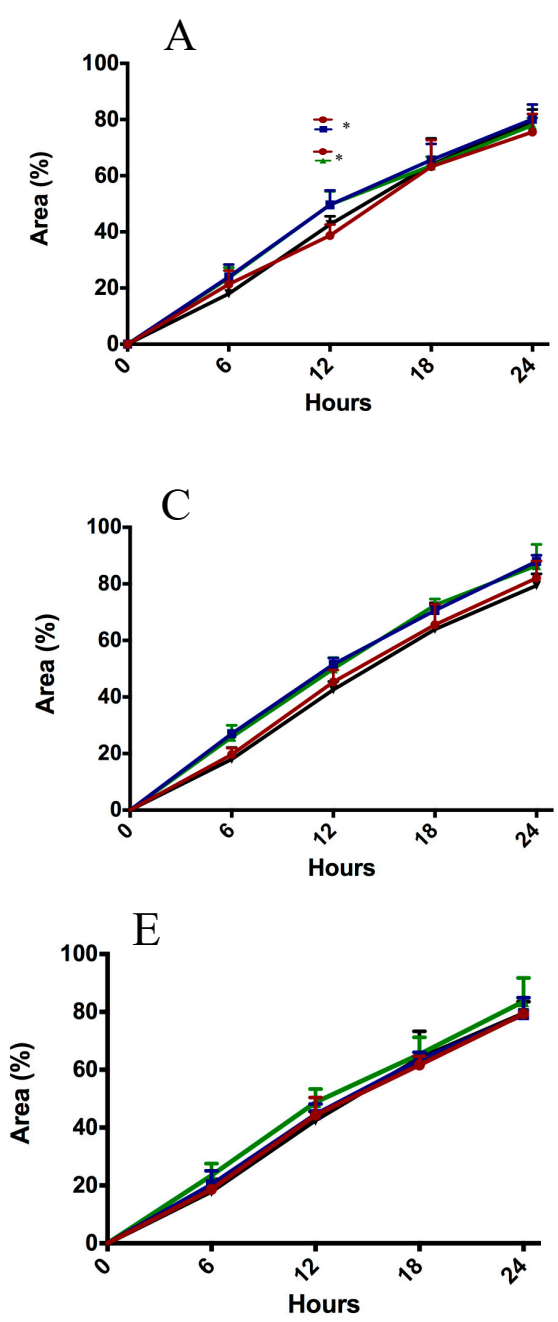

Primary keratinocyte-derived EVs

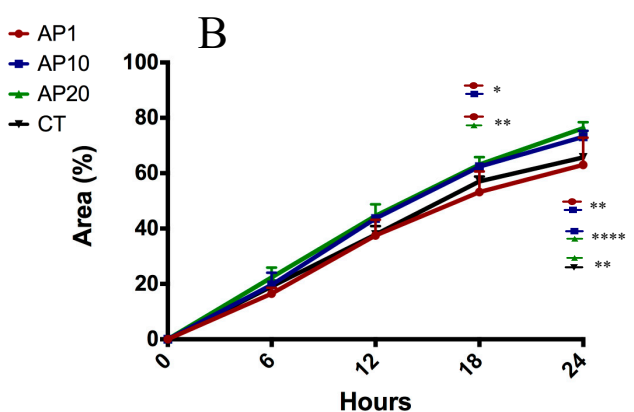

$\rightarrow$ MV1

$-M V 10$

- CT
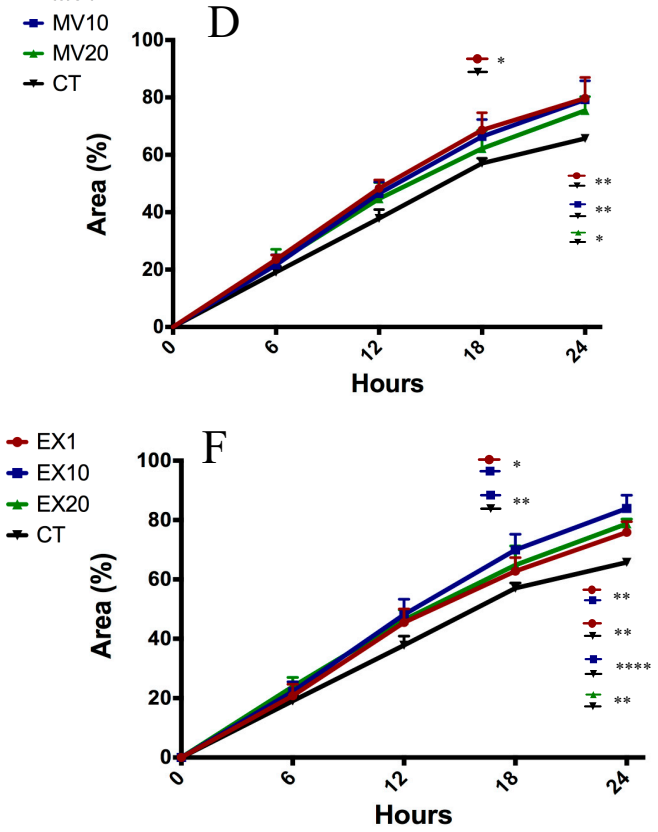

Figure 6. Primary dermal fibroblast migration is modulated by PKC-derived EVs but is not dose dependent. HaCaT- or PKC-derived (A,B) APs, $(\mathbf{C}, \mathbf{D})$ MVs or $(\mathbf{E}, \mathbf{F})$ EXs were added to scratch-wounded primary fibroblast cultures to a final total EV protein concentration of $1 \mu \mathrm{g}, 10 \mu \mathrm{g}$ or $20 \mu \mathrm{g} / 0.1 \mathrm{~mL} \mathrm{DM}$ as indicated. The fibroblasts were incubated at $5 \% \mathrm{CO}_{2}$ and $37^{\circ} \mathrm{C}$ and allowed to migrate for $24 \mathrm{~h}$ with images captured at 6 hourly intervals. Image analysis was performed using ImageJ and data are presented as the mean percent area of wound coverage in $\mu \mathrm{m}^{2} \pm \mathrm{SD}$, from at least 3 independent biological replicates. Two-way ANOVA and Tukey's multiple comparison tests were used to evaluate statistical significance, which is denoted as ${ }^{*}$ where $p<0.05 ;{ }^{* *} p<0.01$; and ${ }^{* * *} p<0.0001$. AP: Apoptotic bodies; MV: Microvesicles; EX: Exosomes; CT: Control.

Of interest, all three EV populations derived from PKCs induced significant fibroblast migration compared to the controls (Figures 6B,D,F and 7). Specifically, PKC-derived APs did not enhance fibroblast migration at doses of $1 \mu \mathrm{g} / 0.1 \mathrm{~mL}$ or $10 \mu \mathrm{g} / 0.1 \mathrm{~mL}$, but did significantly elevate cell migration after $24 \mathrm{~h}$ exposure to a dose of $20 \mu \mathrm{g} / 0.1 \mathrm{~mL}$ compared to the untreated control group $(p<0.01)$ (Figure 6B). The fibroblasts migrated further after $18 \mathrm{~h}$ when treated with $1 \mu \mathrm{g} / 0.1 \mathrm{~mL}$ of PKC-derived MVs $(p<0.01)$, or after the $24 \mathrm{~h}$ when treated with $1 \mu \mathrm{g} / 0.1 \mathrm{~mL}(p<0.001)$ or $20 \mu \mathrm{g} / 0.1 \mathrm{~mL}(p<0.05)$ of PKC-derived MVs (Figure 6D). Enhanced cell migration was also observed in fibroblast cultures after $24 \mathrm{~h}$ treatment with $1 \mu \mathrm{g} / 0.1 \mathrm{~mL}(p<0.01), 10 \mu \mathrm{g} / 0.1 \mathrm{~mL}(p<0.0001)$ and $20 \mu \mathrm{g} / 0.1 \mathrm{~mL}$ of PKC-derived EXs $(p<0.001)$ (Figure 6F, $18 \mathrm{~h} \& 24 \mathrm{~h}$ ). However, the response of human primary dermal fibroblasts to individual EV populations was not clear when a comparison of cell migration was made between APs, 
MVs and EXs released from the same donor cell source and at equivalent concentrations (data not shown).
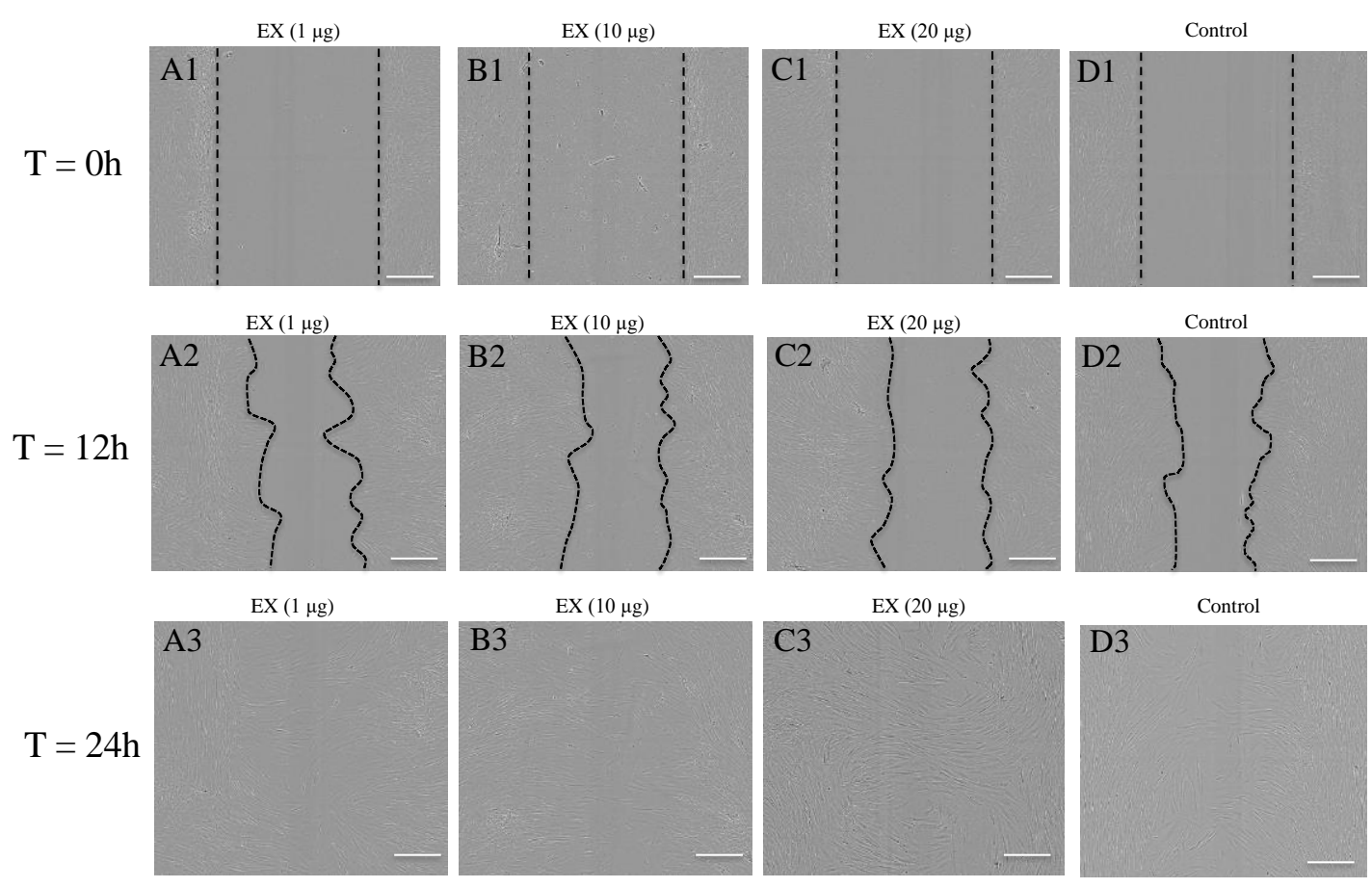

Figure 7. Primary keratinocyte-derived EXs facilitate migration of dermal fibroblasts in 2D culture. Isolated primary keratinocyte-derived EXs were added to scratch-wounded primary fibroblast cultures to a final total EV protein concentration of $1 \mu \mathrm{g}, 10 \mu \mathrm{g}$ or $20 \mu \mathrm{g} / 0.1 \mathrm{~mL}$ depleted media. Fibroblasts cultured within depleted media only served as controls. The wounded fibroblast cultures were incubated at $5 \% \mathrm{CO}_{2}$ and $37^{\circ} \mathrm{C}$ and allowed to migrate for $24 \mathrm{~h}$ in the presence or absence of primary keratinocyte-derived EXs with images captured at 6 hourly intervals. Representative images were extracted from the captured IncuCyte ${ }^{\mathrm{TM}}$ images at $(\mathbf{A 1 , B 1 , C 1 , D 1 )} \mathrm{T}=0 \mathrm{~h} ;(\mathbf{A 2}, \mathbf{B 2}, \mathbf{C 2}, \mathbf{D 2}) \mathrm{T}=12 \mathrm{~h}$; and $(\mathbf{A 3}, \mathbf{B} 3, \mathbf{C} 3, \mathrm{D} 3) \mathrm{T}=24 \mathrm{~h}$. Images were captured using a $4 \mathrm{X}$ objective. The scale bar $=300 \mu \mathrm{m}$ and the dotted lines represent the wound edge.

Taken together, these data indicate that while PKC-derived EVs generally enhanced the migration response of fibroblast cells, the dose responsiveness was relatively inconsistent and therefore did not appear to be dose dependent. Moreover, the extent of the migration response of fibroblasts to EVs is dependent on the EV parental cell source and the duration of the exposure to the EVs.

\section{Discussions}

Over the past few years, several studies have described the expression of miRNAs in EVs [14,15], and recently EV miRNAs have evidently modified functional measures in recipient cells [10]. Our previous study characterised three EV populations released from $\mathrm{HaCaT}$ and PKCs and reported that these EVs carry many miRNA species $[3,16]$. In this current study, we show miRNAs that exhibited high abundances and that were identified in the three EV populations, as well as that these specific EV miRNAs were associated with their parental cellular origin. Of these, approximately $200 \mathrm{EV}$ miRNAs exhibited greater than 100 RPM and 100 miRNAs exhibited greater than 1000 RPM. Despite the large number of abundant miRNAs identified in this current study, how many, and/or which of these are active and regulate target mRNAs, remain an important question. As reported previously, only highly expressed miRNAs seem able to significantly regulate their targets $[13,17,18]$. For instance, Brown et al. demonstrated that only miRNAs that have greater than 100 copies/pg of the short RNA fraction significantly suppressed their targets [17]. Similarly, Mullokandov et al. showed that $80 \%$ of 
miRNAs that have greater than 100 RPM have suppressive activity [13]. In addition, and to further complicate matters, not all highly expressed miRNAs suppress their targets; for example, miRNA-223 was similarly highly expressed in U937 monocyte cells, 293T kidney cells and HuH7 liver cells, but only suppressed its target mRNA in monocyte cells and not in the other cell types [17]. Therefore, the specific suppressive activity, or otherwise, of the miRNAs described in this study is promising but need to be validated.

With regard to the miRNA populations identified in all three keratinocyte-derived EV populations, our previous research indicated that there were 242 unique miRNAs associated with HaCaT-derived EVs and 56 unique miRNAs associated with PKC-derived EVs [3] Importantly, among the most abundant miRNAs, hsa-miR-205 was highly associated with HaCaT whereas the four miRNAs, hsa-miR-21, hsa-miR-203, hsa-miR-22 and hsa-miR-143, were highly associated with PKCs. Several of these miRNAs have been previously reported to be involved in keratinocyte and skin biology [19-22]. The miRNAs (miRNA-205, miRNA-21 and miRNA-203) have been previously found to induce keratinocyte migration, proliferation and differentiation through regulation of various gene targets [19,21-23]. For example, hsa-miR-205 directly silences SH2-domain containing inositol 5-phospatase 2 (SHIP2), resulting in an increase in cell migration [21]; hsa-miR-21 targets the inhibitory Smad and Smad 7 to promote collagen inhibition [24], or targets phosphatase and tensin homolog (PTEN) [25], causing skin fibrosis by fibroblasts [26]; and hsa-miR-203 regulates p63, Ras-related nuclear protein-Ras association (RalGDS/AF-6) and pleckstrin homology domains 1, as well as LIM and SH3 domain protein 1 (LASP1), which are responsible for both keratinocyte proliferation and migration during wound re-epithelialization [23]. Furthermore, miRNA-205 is highly expressed in skin cancer (cutaneous squamous cell carcinoma) [27], and miRNA-21 is highly expressed in injured skin and enhances re-epithelialisation $[20,22]$. These observations may indicate that the EV miRNAs found to originate from both HaCaT cells and PKCs in this current study all have a role in wound healing and skin biology.

These miRNAs have been demonstrated to be involved in many biological events despite the fact that very little practical evidence regarding the association of EV miRNAs and biological events is available; thus, bioinformatic analysis of the genes regulated by EV miRNAs can potentially provide insight as to the relative contribution of EVs and EV miRNAs to various biological activities. For instance, preliminary bioinformatic analysis of genes targeted by miRNAs detected in LIM1863 colon cancer cell line-derived EVs resulted in various enrichment of GO terms, such as extracellular matrix, membrane and cancer progression [14]. Furthermore, important pathways, such as the p53 signalling pathway, TGF-beta signalling pathway, MAPK signalling pathway, cell cycle, among others, have been reported previously as having an association with miRNA-mediated regulation [14,28,29]. In this present study, the BP GO terms enriched by the EV miRNA target genes are associated with the regulation activity, metabolic process, biological process, response to stimulus, organ morphogenesis and development, transport and signalling pathway. However, there are also distinct BP GO terms associated with EV parental cell origin. These disparities may arise from the specific differences in the physiological conditions between the HaCaT cell line, which resemble transformed keratinocytes, and primary keratinocyte cells, that while more biologically relevant exhibit heterogeneity between donors $[30,31]$. Both the experimental and bioinformatic data indicated that fibroblast migration may be regulated by PKC-derived EVs but not by HaCaT-derived EVs, which demonstrates the association of biological processes with EV cellular origin. It is noted that the release of EV and selective sorting of molecular cargo, including miRNAs, into EVs upon stimulation in an unrelated cell type supports the wider role of EVs in human physiology [32,33]. Although bioinformatics information in this current study may serve to indicate the potential connections between EV miRNAs and functional consequences, it is important that experimental corroboration is obtained to have confidence that EV miRNA regulate target genes and biological functions.

Together, the EV miRNA data presented herein provide valuable insights into the EV miRNA composition and point to the potential activity of EV miRNAs in vivo. Data arising from this study revealed differentially abundant EV miRNA populations associated with particular cellular 
types. Importantly, the target genes of the most abundant EV miRNAs differ from their classified function and encode for some important proteins associated with many biological activities, including dermal-epidermal wound healing and fibroblast migration. While the keratinocyte-derived EVs utilised in this study were not produced from a robust wound healing model, the data does still suggest that some EV miRNAs do have a role during cutaneous wound healing.

\section{Materials and Methods}

\subsection{Cell Culture}

Ethical approval for research detailed herein was obtained from Queensland University of Technology (QUT); Pacific Day Surgery/Brisbane Private Hospital (approval \# 1300000063/QUT); Princess Alexandra Hospital (approval \# HREC/06/QPAH/91); and Uniting Health Care's St. Andrews Hospital and Wesley Hospital (approval \# 2003/46).

Epidermal primary keratinocytes (PKCs) were freshly isolated from donor skin (surgical discard) and propagated on $\mathrm{i} 3 \mathrm{~T} 3$ feeder cells $\left(1 \times 10^{6}\right.$ cells/T75 flask $)$ using the method described by Rheinwald and Green [34]: DMEM | Ham's F12 (3:1), supplemented with 10\% foetal calf serum, $2 \mathrm{mM}$ L-glutamine, $1 \% \mathrm{v} / \mathrm{v}$ penicillin-streptomycin, $180 \mu \mathrm{M}$ adenine, $0.5 \mu \mathrm{M}$ insulin, $0.05 \mu \mathrm{M}$ cholera toxin, $0.01 \% \mathrm{v} / \mathrm{v}$ non-essential amino acids solutions, $2.5 \mu \mathrm{g}$ transferrin, $0.1 \mu \mathrm{M}$ triiodothyronine, $0.16 \mu \mathrm{g}$ hydrocortisone and 0.05 ng human recombinant endothelial growth factor [34].

$\mathrm{HaCaT}$ cells were purchased from CLS Cell Lines Service GmbH (Eppenheim, Germany) [35]. HaCaT cells seeded at 1-2 $\times 106$ cells/T75 flask were propagated in DMEM supplemented with 10\% FCS, $1 \%$ pen/strep and $1 \%$ glutamine).

All cultures for both PKCs and $\mathrm{HaCaT}$ were maintained at $37^{\circ} \mathrm{C}$ in a $5 \% \mathrm{CO}_{2} / 95 \%$ air atmosphere, re-fed every 2 days, and sub-cultured when cells reached $80 \%$ confluency.

\subsection{EV Production and Isolation}

EV production and isolation were reported in our previous publication [3]. Briefly, PKCs and $\mathrm{HaCaT}$ were cultured to $80 \%$ confluence; the expired media and i3T3 cells were removed and the remaining PKC cultures washed prior to incubation for $48 \mathrm{~h}$ with serum-free media for EV production. The EV-enriched media released by HaCaT and PKC cultures (conditioned media-CM) were collected and centrifuged at $300 \times g$ for $10 \mathrm{~min}$ to remove cell debris prior to proceeding with EV isolation [36].

EV enriched CM were gravity filtered through a $5 \mu \mathrm{m}$ Durapore ${ }^{\circledR}$ membrane filter (Millipore) then centrifuged at $3000 \times g$ for 40 min prior to collection and resuspension of the of the AP pellets in PBS, and re-centrifugation at $3500 \times g$ for $1 \mathrm{~h}$. The resulting pelleted material was designated as clean "AP-harvest". Supernatants from the AP-harvest were gravity filtered through a $1.2 \mu \mathrm{m}$ Hydrophilic Nylon membrane filter (Millipore) prior to centrifugation of the filtrates at $16,500 \times g$ for $1 \mathrm{~h}$ at $4{ }^{\circ} \mathrm{C}$ (Rotor SW70, Beckman Coulter, Indianapolis, USA). The resulting "MV-harvest" pellets were resuspended in PBS and centrifuged at $16,500 \times \mathrm{g}$ for $1 \mathrm{~h}$ at $4{ }^{\circ} \mathrm{C}$ prior to gravity filtration of resulting supernatants through a $0.1 \mu \mathrm{m}$ Durapore ${ }^{\circledR}$ membrane filter (Millipore). The filtrate was then centrifuged at $100,000 \times g$ for $1.5 \mathrm{~h}$ at $4{ }^{\circ} \mathrm{C}$ to yield "EX-harvest" pellets. The EX pellets were resuspended in PBS and centrifuged at $100,000 \times g$ for $1.5 \mathrm{~h}$ at $4{ }^{\circ} \mathrm{C}$ for clean EXs. Clean AP, MV and EX harvest materials were resuspended in PBS (approximately $30 \mu \mathrm{L}$ ) and stored at $-20^{\circ} \mathrm{C}$ for up to 4 weeks, or at $-80^{\circ} \mathrm{C}$ for longer-term storage.

\subsection{Total RNA Extraction and miRNA Sequencing}

The total RNA extraction using Trizol ${ }^{\mathrm{TM}}$ method and small RNA sequencing using Illumina ${ }^{\circledR}$ Next Seq500 were reported in our previous publication [3]. Briefly, total RNAs were extracted from vesicle pellets using the Trizol ${ }^{\mathrm{TM}}$ method prior to being subjected to an Illumina ${ }^{\circledR}$ TruSeq ${ }^{\circledR}$ Small RNA Library Prep Kit as per the manufacturer's instructions. The RNAs were ligated to adapters prior to reverse transcription to CDNAs and amplified by PCR. The amplified PCR products from this stage 
were referred to as the small RNA library, which was subsequently purified by gel electrophoresis. The bands containing miRNAs between $145 \mathrm{bp}$ and $160 \mathrm{bp}$ were excised and eluted in $200 \mu \mathrm{L}$ pure water. The resulting cDNA library was diluted to $2 \mathrm{nM}$ using a solution of Tris- $\mathrm{HCl} 10 \mathrm{nM}, \mathrm{pH} 8.5$ and $0.1 \%$ Tween 20 prior to loading onto an Illumina chip and sequencing using an Illumina ${ }^{\circledR}$ Next Seq500.

\section{4. miRNA Identification and Statistics}

The raw data generated from the Illumina ${ }^{\circledR}$ Next Seq500 were exported into a FASTQ file. Index and adaptor sequences were then removed using the TagCleaner program (http://tagcleaner.sourceforge. net/index.html, version 0.16) and trimmed to 28 nucleotides using the FASTX-Toolkit program (http://hannonlab.cshl.edu/fastx_toolkit/index.html, version 0.0.13) prior to submission of the cleaned nucleotide data to the miRDeep2 software (version 1.10.1) for subsequent analysis. The sequences were aligned to the human genome (hg19, downloaded from http://bowtie-bio.sourceforge.net/index.shtml) using the mapper and quantifier modules in miRDeep2 to identify and quantified miRNAs.

The identified miRNAs and their raw counts were further analysed using a DESeq2 software and $R$ statistical environment ( $R$ version 3.2.2, last update 14/8/2015) for filtering, normalisation and PCA analysis to test the correlation of identified miRNAs between EVs and their parental cell source.

\subsection{Analysis of miRNA Target Genes}

The miRNAs of interest were searched for its miRbase ID using the miRBase website (www.mirbase. org). These were subsequently analysed using Cytoscape (version 3.2.1) to create an interaction network of the identified miRNAs and their target genes. The target database (version 6.0) was downloaded from the miRTarBase website (accessed 5/1/2016, http://mirtarbase.mbc.nctu.edu.tw). miRTarbase is an experimentally validated miRNA-target interaction database that was updated recently (released 15/9/2015 for version 6). The data were exported as an image of the target gene-miRNA interaction network and as an excel file of target genes.

A target gene list was then classified into similar functional groups using the DAVID Bioinformatics Resources version 6.8 (https://david-d.ncifcrf.gov/) based on the whole Homo sapiens genome background [37,38]. The Functional Classification Tool was used with Kapa similarity term overlap set to 4 and Kapa similarity threshold set to 0.35 , classification parameters were set to initial group membership at 4; final group membership at 4; multiple linkage threshold set to 0.5 ; and the classification stringer was set to medium.

The target gene list was also analysed for Biological Processes (BPs) and network visualisation using Cytoscape BiNGO (version 3.2.1). The Gene Ontology (GO) database was download from the official website of Gene Ontology (go-basic.obo, http://geneontology.org/page/download-ontology, downloaded 28/3/2017). The GO annotation database was downloaded from the Gene Ontology website (http://geneontology.org/page/download-annotations, version released 13/3/2017, downloaded 28/3/2017; go_basic.obg, goa_human.gaf (annotation), which contain 19,318 annotated products). The Benjamini and Hochberg False Discovery Rate was used for correction and the $p$-value cut off was at 0.05 .

\subsection{Scratch-Wound Assay}

Primary human dermal fibroblasts isolated from individual human donors were harvested as described above and propagated until a sufficient number of cells (passage 4) were available to seed 96 well ImageLock plates (Essen BioScience, Michigan, USA). The fibroblast culture media used for the scratch assay cultures were comprised of similar components to normal fibroblast culture media (NM), which included DMEM, 10\% FCS, 1\% Pen/Strep and 1\% L-glutamine. Since FCS may contain endogenous EVs that might influence cell function, depleted media (DM) was prepared by subjecting FCS to centrifugation at $120,000 \times \mathrm{g}$ for $24 \mathrm{~h}$ at $4{ }^{\circ} \mathrm{C}$ before addition of the collected supernatant to culture media [39]. Cells were cultured to 100\% confluence and the treated with $10 \mu \mathrm{g}$ Mitomycin C (Sigma Aldrich) in order to inhibit further cell proliferation. Scratch wounds were then created simultaneously 
in each well using a WoundMaker ${ }^{\mathrm{TM}}$ device (Essen Bioscience). Closure of the "wounded" monolayer of primary human dermal fibroblasts, in the presence (and absence) of $1 \mu \mathrm{g}, 10 \mu \mathrm{g}$ or $20 \mu \mathrm{g} \mathrm{EV}$ protein per well ( $0.1 \mathrm{~mL}$ cell culture media), was monitored using an IncuCyte ${ }^{\mathrm{TM}}$ Zoom instrument (Essen Bioscience). CSV data was imported into Excel (Microsoft) and Wound Relative Density used to calculate wound closure parameters throughout the experiment. Image analysis was performed using ImageJ and data were presented as the mean percent area of wound coverage in $\mu \mathrm{m}^{2} \pm \mathrm{SD}$, from at least 3 independent biological replicates. Two-way ANOVA and Tukey's multiple comparison tests were used to evaluate statistical significance.

Supplementary Materials: The following are available online at http:/www.mdpi.com/1422-0067/21/3/1141/s1, Supplemental Table S1: Target genes regulated by hsa-miR-205, Supplemental Table S2: Target genes regulated by hsa-miR-21, by hsa-miR-203, by hsa-miR-21 and by hsa-miR-143, Supplemental Table S3: Biological processes associated with target genes regulated by hsa-miR-205.

Author Contributions: All authors contributed to the study design; U.T.T.T. performed the experiment work and data analysis; D.G. performed sequencing data analysis; U.T.T.T., D.G., J.A.B., T.J.P. and D.I.L. drafted the manuscript; T.J.P. and D.I.L. edited the manuscript; all authors contributed to interpretation of data. All authors have read and agreed to the published version of the manuscript.

Funding: This research was funded by Wound Management Innovation CRC-Australia, project SP22-1.

Acknowledgments: The authors would like to acknowledge the support of the Australian Government's Cooperative Research Centre Programme.

Conflicts of Interest: The authors declare no conflict of interest. The founding sponsors had no role in the design of the study; in the collection, analyses, or interpretation of data; in the writing of the manuscript, and in the decision to publish the results. This manuscript is not currently submitted elsewhere and none of the paper's content have been previously published.

$\begin{array}{ll}\text { Abbreviations } \\ \text { AP(s) } & \text { Apoptotic Bodies } \\ \text { BP } & \text { Biological process } \\ \text { CM } & \text { Conditioned medium } \\ \text { ECM } & \text { Extracellular matrix } \\ \text { EX(s) } & \text { Exosome(s) } \\ \text { EV(s) } & \text { Extracellular membrane vesicle(s) } \\ \text { GO } & \text { Gene Ontology } \\ \text { MAPK } & \text { Mitogen-activated protein kinase } \\ \text { miRNA } & \text { microRNAs } \\ \text { MV(s) } & \text { Microvesicle(s) } \\ \text { PCA } & \text { Principal component analysis } \\ \text { PBS } & \text { Phosphate -saline } \\ \text { PKC(s) } & \text { Primary keratinocyte(s) } \\ \text { PTEN } & \text { Phosphatase and tensin homolog } \\ \text { RPM } & \text { Read per million } \\ \text { SHIP2 } & \text { SH2-domain containing inositol 5-phospatase 2 } \\ \text { TGF-beta } & \text { Transforming growth factor beta }\end{array}$

\section{References}

1. Chávez-Muñoz, C.; Morse, J.; Kilani, R.; Ghahary, A. Primary human keratinocytes externalize stratifin protein via exosomes. J. Cell. Biochem. 2008, 104, 2165-2173. [CrossRef]

2. Cicero, A.L.; Delevoye, C.; Gilles-Marsens, F.; Loew, D.; Dingli, F.; Guéré, C.; Andre, N.; Vie, K.; Van Niel, G.; Raposo, G. Exosomes released by keratinocytes modulate melanocyte pigmentation. Nat. Commun. 2015, 6, 7506. [CrossRef] [PubMed]

3. Than, U.T.; Guanzon, D.; Broadbent, J.A.; Leavesley, D.I.; Salomon, C.; Parker, T.J. Differential expression of keratinocyte-derived extracellular vesicle mirRNAs discriminate exosomes from apoptotic bodies and microvesicles. Front. Endocrinol. 2018, 9, 535. [CrossRef] [PubMed] 
4. Akers, J.C.; Gonda, D.; Kim, R.; Carter, B.S.; Chen, C.C. Biogenesis of extracellular vesicles (EV): Exosomes, microvesicles, retrovirus-like vesicles, and apoptotic bodies. J. Neuro-Oncol. 2013, 113, 1-11. [CrossRef] [PubMed]

5. György, B.; Kittel, A.; Nagy, G.; Falus, A.; Buzás, E.I.; Szabó, T.G.; Pásztói, M.; Pál, Z.; Misják, P.; Aradi, B.; et al. Membrane vesicles, current state-of-the-art: Emerging role of extracellular vesicles. CMLS 2011, 68, 2667-2688. [CrossRef]

6. Yáñez-Mó, M.; Siljander, P.R.-M.; Andreu, Z.; Zavec, A.B.; Borràs, F.E.; Buzas, E.I.; Buzas, K.; Casal, E.; Cappello, F.; Carvalho, J.; et al. Biological properties of extracellular vesicles and their physiological functions. J. Extracell. Vesicles 2015, 4, 27066. [CrossRef]

7. Than, U.T.T.; Guanzon, D.; Leavesley, D.; Parker, T. Association of extracellular membrane vesicles with cutaneous wound healing. Int. J. Mol. Sci. 2017, 18, 956. [CrossRef]

8. Valadi, H.; Ekström, K.; Bossios, A.; Sjöstrand, M.; Lee, J.J. Exosome-mediated transfer of mRNAs and microRNAs is a novel mechanism of genetic exchange between cells. Nat. Cell Biol. 2007, 9, 654-659. [CrossRef]

9. Bartel, D.P. MicroRNAs: Target recognition and regulatory functions. Cell 2009, 136, 215-233. [CrossRef]

10. Liang, X.; Zhang, L.; Wang, S.; Han, Q.; Zhao, R.C. Exosomes secreted by mesenchymal stem cells promote endothelial cell angiogenesis by transferring miR-125a. J. Cell Sci. 2016, 129, 2182-2189. [CrossRef]

11. Chávez-Muñoz, C.; Kilani, R.T.; Ghahary, A. Profile of exosomes related proteins released by differentiated and undifferentiated human keratinocytes. J. Cell. Physiol. 2009, 221, 221-231. [CrossRef] [PubMed]

12. Liu, Y.; Xue, L.; Gao, H.; Chang, L.; Yu, X.; Zhu, Z.; He, X.; Geng, J.; Dong, Y.; Li, H.; et al. Exosomal miRNA derived from keratinocytes regulates pigmentation in melanocytes. J. Dermatol. Sci. 2019, 93, 159-167. [CrossRef] [PubMed]

13. Mullokandov, G.; Baccarini, A.; Ruzo, A.; Jayaprakash, A.D.; Tung, N.; Israelow, B.; Evans, M.J.; Sachidanandam, R.; Brown, B.D. High-throughput assessment of microRNA activity and function using microRNA sensor and decoy libraries. Nat. Methods 2012, 9, 840-846. [CrossRef] [PubMed]

14. Ji, H.; Chen, M.; Greening, D.W.; He, W.; Rai, A.; Zhang, W.; Simpson, R.J. Deep Sequencing of RNA from Three Different Extracellular Vesicle (EV) Subtypes Released from the Human LIM1863 Colon Cancer Cell Line Uncovers Distinct Mirna-Enrichment Signatures. PLoS ONE 2014, 9, e110314. [CrossRef]

15. Lunavat, T.R.; Cheng, L.; Kim, D.-K.; Bhadury, J.; Jang, S.C.; Lässer, C.; Sharples, R.A.; López, M.D.; Nilsson, J.; Gho, Y.S.; et al. Small RNA deep sequencing discriminates subsets of extracellular vesicles released by melanoma cells-Evidence of unique microRNA cargos. RNA Biol. 2015, 12, 810-823. [CrossRef]

16. Than, U.T.; Guanzon, D.; Wager, L.; Manton, K.J.; Hollier, B.G.; Leavesley, D.I. An Analysis of Exosomes From Keratinocytes And Fibroblasts. In IFMBE_5th International Conference on Biomedical Engineering in Vietnam; Springer International Publishing: Basel, Switzerland, 2015; Volume 46.

17. Brown, B.D.; Gentner, B.; Cantore, A.; Colleoni, S.; Amendola, M.; Zingale, A.; Baccarini, A.; Lazzari, G.; Galli, C.; Naldini, L. Endogenous microRNA can be broadly exploited to regulate transgene expression according to tissue, lineage and differentiation state. Nat. Biotechnol. 2007, 25, 1457-1467. [CrossRef]

18. Hafner, M.; Landthaler, M.; Burger, L.; Khorshid, M.; Hausser, J.; Berninger, P.; Rothballer, A.; Ascano, M.; Jungkamp, A.-C.; Munschauer, M.; et al. Transcriptome-wide identification of RNA-binding protein and microRNA target sites by PAR-CLIP. Cell 2010, 141, 129-141. [CrossRef]

19. Lena, A.M.; Shalom-Feuerstein, R.; Cervo, P.R.d.; Aberdam, D.; Knight, R.A.; Melino, G.; Candi, E. miR-203 represses 'stemness' by repressing DeltaNp63. Cell Death Differ. 2008, 15, 1187. [CrossRef]

20. Yang, X.; Wang, J.; Guo, S.-L.; Fan, K.-J.; Li, J.; Wang, Y.-L.; Teng, Y.; Yang, X. miR-21 Promotes keratinocyte migration and re-epithelialization during wound healing. Int. J. Boil. Sci. 2011, 7, 685-690. [CrossRef]

21. Yu, J.; Peng, H.; Ruan, Q.; Fatima, A.; Getsios, S.; Lavker, R.M. MicroRNA-205 promotes keratinocyte migration via the lipid phosphatase SHIP2. FASEB J. 2010, 24, 3950-3959. [CrossRef]

22. Wang, T.; Feng, Y.; Sun, H.; Zhang, L.; Hao, L.; Shi, C.; Wang, J.; Li, R.; Ran, X.; Su, Y.; et al. miR-21 Regulates Skin Wound Healing by Targeting Multiple Aspects of the Healing Process. Am. J. Pathol. 2012, 181, 1911-1920. [CrossRef] [PubMed]

23. Viticchiè, G.; Lena, A.M.; Cianfarani, F.; Odorisio, T.; Annicchiarico-Petruzzelli, M.; Melino, G.; Candi, E. MicroRNA-203 contributes to skin re-epithelialization. Cell Death Dis. 2012, 3, e435. [CrossRef] [PubMed] 
24. Liu, G.; Friggeri, A.; Yang, Y.; Milosevic, J.; Ding, Q.; Thannickal, V.J.; Kaminski, N.; Abraham, E. miR-21 mediates fibrogenic activation of pulmonary fibroblasts and lung fibrosis. J. Exp. Med. 2010, 207, 1589-1597. [CrossRef] [PubMed]

25. Ma, X.; Kumar, M.; Choudhury, S.N.; Buscaglia, L.E.B.; Barker, J.R.; Kanakamedala, K.; Liu, M.-F.; Li, Y. Loss of the miR-21 allele elevates the expression of its target genes and reduces tumorigenesis. Proc. Natl. Acad. Sci. 2011, 108, 10144-10149. [CrossRef]

26. Parapuram, S.K.; Shi-Wen, X.; Elliott, C.; Welch, I.D.; Jones, H.; Baron, M.; Denton, C.P.; Abraham, D.J.; Leask, A. Loss of PTEN expression by dermal fibroblasts causes skin fibrosis. J. Investig. Dermatol. 2011, 131, 1996-2003. [CrossRef]

27. Bruegger, C.; Kempf, W.; Spoerri, I.; Arnold, A.W.; Itin, P.H.; Burger, B. MicroRNA expression differs in cutaneous squamous cell carcinomas and healthy skin of immunocompetent individuals. Exp. Dermatol. 2013, 22, 426-428. [CrossRef]

28. Harris, S.L.; Levine, A.J. The p53 pathway: Positive and negative feedback loops. Oncogene 2005, 24, 2899-2908. [CrossRef]

29. De Caestecker, M.P.; Piek, E.; Roberts, A.B. Role of transforming growth factor-beta signaling in cancer. J. Natl. Cancer Inst. 2000, 92, 1388-1402. [CrossRef]

30. Seo, M.-D.; Kang, T.-J.; Lee, C.-H.; Lee, A.-Y.; Noh, M.-S. HaCaT keratinocytes and primary epidermal keratinocytes have different transcriptional profiles of cornified envelope-associated genes to Thelper cell cytokines. Biomol. Ther. 2012, 20, 171-176. [CrossRef]

31. Sprenger, A.; Weber, S.; Zarai, M.; Engelke, R.; Nascimento, J.M.; Gretzmeier, C.; Hilpert, M.; Boerries, M.; Has, C.; Busch, H.; et al. Consistency of the proteome in primary human keratinocytes with respect to gender, age, and skin localization. Mol. Cell. Proteom. 2013, 12, 2509-2521. [CrossRef]

32. Shahjin, F.; Guda, R.S.; Schaal, V.L.; Odegaard, K.; Clark, A.; Gowen, A.; Xiao, P.; Lisco, S.J.; Pendyala, G.; Yelamanchili, S.V. Brain-derived extracellular vesicle microRNA signatures associated with in utero and postnatal oxycodone exposure. Cells 2019, 9, 21. [CrossRef] [PubMed]

33. Shahjin, F.; Chand, S.; Yelamanchili, S.V. Extracellular vesicles as drug delivery vehicles to the central nervous system. J. Neuroimmune Pharmacol. 2019, 1-16. [CrossRef] [PubMed]

34. Rheinwald, J.G.; Green, H. Serial cultivation of strains of human epidermal keratinocytes: The formation of keratinizing colonies from single cells. Cell 1975, 6, 331-343. [CrossRef]

35. Boukamp, P.; Petrussevska, R.T.; Breitkreutz, D.; Hornung, J.; Markham, A.; Fusenig, N.E. Normal keratinization in a spontaneously immortalized aneuploid human keratinocyte cell line. J. Cell Boil. 1988, 106, 761-771. [CrossRef]

36. Chiba, M.; Kimura, M.; Asari, S. Exosomes secreted from human colorectal cancer cell lines contain mRNAs, microRNAs and natural antisense RNAs, that can transfer into the human hepatoma HepG2 and lung cancer A549 cell lines. Oncol. Rep. 2012, 28, 1551-1558. [CrossRef]

37. Huang, D.W.; Sherman, B.T.; Lempicki, R.A. Bioinformatics enrichment tools: Paths toward the comprehensive functional analysis of large gene lists. Nucleic Acids Res. 2009, 37, 1-13. [CrossRef]

38. Huang, D.; Sherman, B.; Lempicki, R. Systematic and integrative analysis of large gene lists using DAVID Bioinformatics Resources. Nat. Protoc. 2009, 4, 44-57. [CrossRef]

39. Shelke, G.V.; Lässer, C.; Gho, Y.S.; Lötvall, J. Importance of exosome depletion protocols to eliminate functional and RNA-containing extracellular vesicles from fetal bovine serum. J. Extracell. Vesicles 2014, 3, 24783. [CrossRef]

(C) 2020 by the authors. Licensee MDPI, Basel, Switzerland. This article is an open access article distributed under the terms and conditions of the Creative Commons Attribution (CC BY) license (http://creativecommons.org/licenses/by/4.0/). 